\title{
Experimental investigation of the effect of henna leaf extracts on cuttings transportation in highly deviated and horizontal wells
}

\author{
Jeffrey O. Oseh ${ }^{1,2} \cdot$ M. N. A. Mohd Norrdin ${ }^{1} \cdot$ Farzok Farooqi $^{1} \cdot$ Razak A. Ismail $^{1} \cdot$ Issham Ismail $^{1}$ \\ Afeez O. Gbadamosi ${ }^{1,2} \cdot$ Augustine J. Agi $^{1}$
}

Received: 31 August 2018 / Accepted: 18 February 2019 / Published online: 23 February 2019

(c) The Author(s) 2019

\begin{abstract}
Henna leaf extracts (HLE) was used to formulate henna water-based mud (HWBM) and its performance on cuttings transport efficiency (CTE) was compared with bentonite water-based mud (BWBM) and fresh water. Tests were conducted in a laboratory-scale flow-loop equipped with a 16-ft-long test section consisting of a concentric annulus outer casing (3.5-in. ID) and a static inner drill-pipe (2.4-in. OD) at hole-angles of $0^{\circ}, 45^{\circ}, 60^{\circ}, 75^{\circ}$ and $90^{\circ}$ with annular fluid velocities $(1.1,1.54$, 1.98 and $2.31 \mathrm{ft} / \mathrm{s}$ ) using a cuttings size diameter of $1.0 \mathrm{~mm}$. Experimental results showed that HWBM have better rheological and filtration properties before and after thermal aging tests than BWBM. Plastic viscosity (PV) was $7.4 \mathrm{cP}$ for BWBM and $6.5 \mathrm{cP}$ for HWBM. Apparent viscosity (AV) of BWBM was $12.7 \mathrm{cP}$ and $13 \mathrm{cP}$ for HWBM. The yield point (YP) of BWBM was $10.5 \mathrm{lb} / 100 \mathrm{ft}^{2}$ and $12.2 \mathrm{lb} / 100 \mathrm{ft}^{2}$ for HWBM, while high pressure high temperature (HPHT) filtrates volume of HWBM was increased by $70.4 \%$ from 5.4 to $9.2 \mathrm{ml}$ but, that of BWBM was increased by $94.4 \%$ from 7.1 to $13.8 \mathrm{ml}$. After heating, the PV of BWBM and HWBM decreased by $6.76 \%$ and $1.54 \%$, respectively. The YP of BWBM and HWBM was reduced by $21 \%$ and $4.1 \%$, respectively. $45^{\circ}$ was the most challenging hole-angle, which needs attention while preparing drilling mud. The findings reported in this study could open new areas of research, in particular HLE additive to boost the drilling industry.
\end{abstract}

Keywords Cuttings transport efficiency $\cdot$ Annular fluid velocity $\cdot$ Hole-angles $\cdot$ Henna leaf extracts $\cdot$ Rheological properties

$\begin{array}{ll}\text { Abbreviations } \\ \text { 10-min GS } & 10 \text {-min gel strength } \\ \text { 10-s GS } & 10 \text {-sec gel strength } \\ \text { API } & \text { American petroleum institute } \\ \text { BWBM } & \text { Bentonite water-based mud } \\ \text { CoF } & \text { Coefficient of friction } \\ \text { CTE } & \text { Cuttings transport efficiency } \\ \text { FCT } & \text { Filter cake thickness (mm) } \\ \text { FL } & \text { Filtrates loss (ml) } \\ \text { FTIR } & \text { Fourier transform infrared spectroscopy } \\ \text { GS } & \text { Gel strength }\left(1 \mathrm{~b} / 100 \mathrm{ft}^{2}\right) \\ \text { HLE } & \text { Henna leaf extracts } \\ \text { Hp } & \text { Horse-power }\end{array}$

M. N. A. Mohd Norrdin anam@utm.my

1 Department of Petroleum Engineering, School of Chemical and Energy Engineering, Universiti Teknologi Malaysia, 81310 UTM Skudai, Johor, Malaysia

2 Department of Chemical and Petroleum Engineering, College of Engineering, Afe Babalola University, P.M.B. 5454, Ado-Ekiti, Ekiti State, Nigeria

$\begin{array}{ll}\text { HPHT } & \text { High pressure high temperature } \\ \text { HWBM } & \text { Henna leaf extracts water-based mud } \\ \mathrm{ID} & \text { Inner diameter } \\ \mathrm{KCl} & \text { Potassium chloride } \\ M_{\mathrm{i}} & \text { Weight of injected cuttings in gram } \\ M_{\mathrm{r}} & \text { Weight of recovered cuttings in gram } \\ \mathrm{NaOH} & \text { Sodium hydroxide/caustic soda } \\ \mathrm{OD} & \text { Outer diameter } \\ \mathrm{PAC} & \text { Polyanionic cellulose } \\ \mathrm{PV} & \text { Plastic viscosity }(\mathrm{cP}) \\ \mathrm{TGA} & \text { Thermal gravimetric analysis } \\ \text { WBM } & \text { Water-based mud } \\ \text { YP } & \text { Yield point }\left(\mathrm{lb} / 100 \mathrm{ft}^{2}\right)\end{array}$

\section{Introduction}

One of the major components during wellbore drilling for oil and gas in an oilfield is the drilling fluid (Caenn et al. 2017). They are indispensable and play crucial roles in drilling operations. These roles include, but are not limited to; cooling and lubricating the drill bit and drill string to

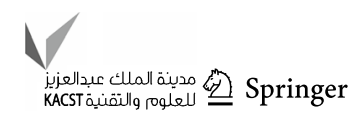


minimize wear, and creating and ensuring overbalanced drilling conditions to control formation pressure (Chilingarian and Vorabutr 1983). Furthermore, they carry downhole information to the surface for interpretation in the form of signals from drilled wells. Besides, they seal off permeable formations by forming a low permeable and thin mud cake at the borehole of the permeable formations (Caenn et al. 2017; Chilingarian and Vorabutr 1983). More importantly, they suspend drilled cuttings when circulation is pause, and circulate the drilled cuttings from the wellbore to the surface from where they are treated for recirculation or disposal (Caenn et al. 2017; Chilingarian and Vorabutr 1983; Gatlin 1960).

Effective drilled cuttings removal from the wellbore has been reported to be a key challenge in drilling operations (Duan et al. 2008; Gbadamosi et al. 2018a, b; Hakim et al. 2018). This challenge appears to have being well examined in case of straight hole-angle (Belavadi and Chukwu 1994), but in the case of highly deviated and horizontal portions of the well, removal of drilled cuttings is still a major problem (Ismail et al. 2016). Also, when drilling in highly deviated and horizontal portions of the annulus, the cleaning of the well worsens with increasing well depth and hole deviation (Ismail et al. 2016; Onuoha et al. 2015; Gavignet and Sobey 1989). Application of this form of drilling system is in most cases linked with serious drilling problems which often affect the performance of drilling muds. High torque and drag, barite sag, formation damage, lost circulation, slow drilling rate, increased equivalent circulating density (ECD), kick leading to blowout if not properly controlled, hole instability, and in terrible situation, differential stuck pipe, are several of the problems faced while drilling in highly deviated or horizontal wells (Ismail et al. 2016; Onuoha et al. 2015; Gavignet and Sobey 1989; Ford et al. 1990). If these problems are not properly addressed, it can get worse and probably lead to well side tracking or even loss of the entire well (Gatlin 1960). Thus, appropriate design of drilled cuttings transport strategy, such as incorporating optimum drilling fluid properties with the best drilling practice is crucial to obtaining a successful drilling operation.

Decreased fluid velocity at the low side of the wall have been reported in numerous literatures to be the main cause of poor cuttings transportation with increasing hole-angle (Duan et al. 2008; Ismail et al. 2016; Ford et al. 1990; Gavignet and Sobey 1989; Onuoha et al. 2015). Gbadamosi et al. (2018b), Hakim et al. (2018), Elochukwu et al. (2017), Afolabi et al. (2017), Ismail et al. (2016) and Piroozian et al. (2012) all reported that the rheological and filtration properties of drilling fluids have significant contributions in determining the effectiveness of cuttings transportation. The rheological properties are often optimized to ensure that drilling fluid can function effectively and yet lessen the drilling cost. Williams and Bruce (1951) reported that an established minimum annular fluid velocity should be used to transport drilled cuttings from the hole. Turbulent flow was their preference for better cuttings transportation. They recommended laminar flow for near vertical and vertical annulus, and turbulent flow for near horizontal and horizontal annulus.

Over the years, two major drilling muds, namely, waterbased muds (WBMs) and oil-based muds (OBMs) are commonly used for effective drilled cuttings stimulation downhole (Dosunmu and Ogunrinde 2010; Rabia 1985; Sayindla et al. 2017). OBMs and WBMs were reported to behave in different ways in terms of cuttings transportation despite their velocity distribution in the annulus to have been pretty similar (Rabia 1985). The dissimilarity in the behaviour of both OBM and WBM is ascribed to the manner of designing the drilling muds (Sulaimon et al. 2017; Christiansen 1991; Sayindla et al. 2017). OBMs exhibit a higher cuttings lifting efficiency compared with WBMs (Sulaimon et al. 2017; Gatlin 1960; Caenn et al. 2017). However, the toxic nature of OBM effluents and higher operational costs than WBM have limited its general acceptability as the mud carrying capacity of drilled cuttings. These have resulted in the increased search for eco-friendlier WBM with proper formulations (Christiansen 1991). Another remarkable attribute of WBM is the ease at which its characteristics can be modified (Chilingarian and Vorabutr 1983).

For the past years, two common polymers have been widely investigated for use as additives for improving properties of drilling fluid. They are synthetic (man-made) polymers and biological (organic) polymers (Garcia-Ochoa et al. 2000; Luz et al. 2017). Numerous works had been done with the use of both synthetic and natural polymers to enhance the rheological properties of WBMs with the introduction of typical additives termed 'viscosity modifiers' to improve the rheological properties of the mud systems (Garcia-Ochoa et al. 2000; Luz et al. 2017; Fereydouni et al. 2012).

A naturally occurring bio-based polymers, such as carboxyl methyl cellulose (CMC) (Luz et al. 2017), polyanionic cellulose (PAC) (Fereydouni et al. 2012), and xanthan gum (Garcia-Ochoa et al. 2000) have been widely studied for cuttings transportation. With increasing restrictions of environmentally toxic additives, natural viscosity modifiers have gained increased attention within the drilling industry (Luz et al. 2017). Therefore, bio-based polymeric viscosifiers can be introduced to drill in areas with stringent environmental control in terms of disposal of drilling fluids effluents. In a situation where environmental control is not an important factor, the cost of treating the drilling mud prior to disposal can be minimized, eliminated or saved with the use of organic polymers.

HLE (Lawsonia inermis L.) plant is a proven environmentally benign and low-cost polymer (Avci et al. 2013). It is an odoriferous plant of Lythraceae family. It is a small tree or shrub with spine-tipped branches and $200-600 \mathrm{~cm}$ 
high. It has a smooth leaf often described to be opposite sub-sessile, shaped elliptically and approximately lanceolate, with depressed veins that can be seen clearly from the dorsal surface (Labed et al. 2016; Semwal et al. 2014; Mehrdad et al. 2014). Henna plants are mostly cultivated in Egypt, Iran, Nigeria, Yemen, Algeria, Afghanistan, Pakistan, etc. (Labed et al. 2016). HLE have been proven to contain Lawsone, gallic acid, glucose, resins, mucilage, tannic acid, fats and traces of alkaloids (Moslemizadeh et al. 2016). Ostovari et al. (2009) reported that the main constituents of HLE are gallic acid (3,4,5-trihydroxy benzoic acid, $\left.\mathrm{C}_{7} \mathrm{H}_{6} \mathrm{O}_{5}\right)$, Lawsone (2-hydroxy-1,4-naphthoquinone, $\mathrm{C}_{10} \mathrm{H}_{6} \mathrm{O}_{3}$ ), tannic acid, and dextrose $\left(\alpha\right.$-D-glucose, $\left.\mathrm{C}_{6} \mathrm{H}_{12} \mathrm{O}_{6}\right)$.

HLE is mainly known for tattooing applications (Ali et al. 2009). Its usage can also be extended for treatment purposes, such as antimicrobial agents (Semwal et al. 2014), drug and dyes (Chaudhary et al. 2010). HLE have been proven to be a low cost, eco-friendly, a naturally occurring material, and commercially available to formulate drilling fluids for drilling operations (Moslemizadeh et al. 2015, 2016; Aghajafari et al. 2016). HLE have been utilized with remarkable success as a shale swelling inhibitor, filtrates loss reducing agent, and lubricity enhancer (Moslemizadeh et al. 2016). HLE is soluble in water and compatible with WBM and can enhance the lubricity of WBM (Moslemizadeh et al. 2016). The lubricity of drilling mud is very important for deviated, highly deviated portions of the well or for horizontal drilling often characterized with constant drill-string in contact with the wall of the wellbore. Results of different shale inhibition tests revealed that HLE has the potential to inhibit shale swelling (Moslemizadeh et al. 2016). This can be achieved when HLE through hydrogen bonding between its constituent hydroxyl $(-\mathrm{OH})$ groups and presence of oxygen atoms on the surface of silica $\left(\mathrm{SiO}_{2}\right)$ mainly composed of montmorillonite attach on shale (coating of the shale particles surface). This attachment can result in shale hydrophobicity and stability.

Aghajafari et al. (2016) pointed out that HLE acted as corrosion inhibitor in metallic medium and improved the resistance of cement slurry against acid attack. Synthesis and characterization studies carried out by Mehrdad et al. (2014) on HLE for thermal stability and solubility in water indicated that the coloured HLE displayed high degree of thermal stability and solubility in water. These characteristics of HLE coupled with their earlier mentioned features could be vital for stability in rheological properties of drilling muds, and a good candidate for cuttings transportation.

However, despite these mentioned wide-ranging applications of HLE as a potential drilling fluid additive, only few studies have been reported on the applications of HLE bearing mud sample for cuttings transportation, in particular for a complete (vertical, deviated, highly deviated and

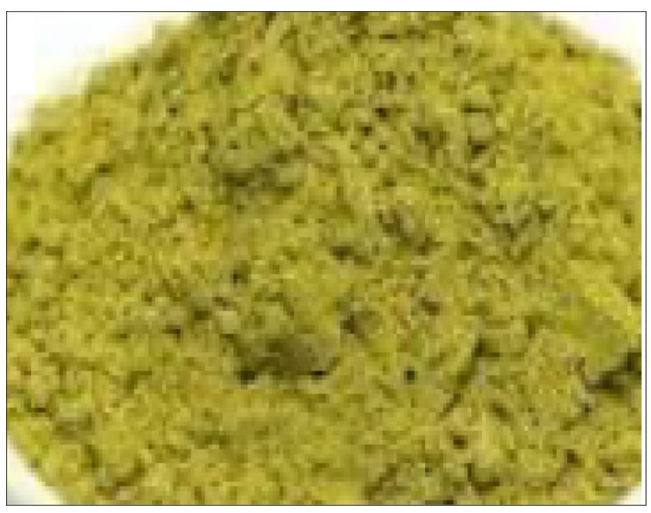

Fig. 1 HLE sample

Table 1 HLE properties

\begin{tabular}{ll}
\hline Product & Dry HLE \\
Used part & Leaf \\
Colour & Brown \\
Odour & Specific odour \\
Solubility in water & Soluble \\
Solubility in alcohol & Soluble \\
$\mathrm{pH}(30 \mathrm{~g} / \mathrm{L})$ & 5.0 \\
Total ash $\left(550^{\circ} \mathrm{C} / 4 \mathrm{~h}\right)$ & $14.36 \%$ \\
Description & Fine powder \\
Application & Hair dye, body paint, tattoo, \\
& dye, special shampoo, anti- \\
& corrosion \\
\hline
\end{tabular}

horizontal) wellbore. Therefore, this study used HLE additive to formulate henna water-based mud and compared its performance on CTE with bentonite water-based mud and fresh water at various hole-angles $\left(0^{\circ}, 45^{\circ}, 60^{\circ}, 75^{\circ}\right.$, and $\left.90^{\circ}\right)$ and different annular fluid velocities $(1.1 \mathrm{ft} / \mathrm{s}, 1.54$ $\mathrm{ft} / \mathrm{s}, 1.98 \mathrm{ft} / \mathrm{s}$ and $2.31 \mathrm{ft} / \mathrm{s}$ ).

\section{Experimental details}

\section{Materials}

Bentonite, HLE powder (Fig. 1), caustic soda $(\mathrm{NaOH})$, polyanionic cellulose (PAC), potassium chloride $(\mathrm{KCl})$ and barite. These additives were obtained from Sigma Aldrich (Merck), Sdn. Bhd. Malaysia. In this study, the HLE powder was obtained from Saeed Ghani pharmaceutical company, Islamabad, Pakistan, and its major properties are provided in Table 1. 


\section{Drilled cuttings sample}

The aquarium sand used in this study as drilled cuttings sample is shown in Fig. 2. Aquarium sands are naturally occurring and are easy to clean. It takes in water and its carbonates are usually fine chips of sea shell and corel. It is readily available and is one of the cheapest forms of aggregate on earth. It is made up of freshwater and small amounts of salt water. Its contact with salt-water mud can increase the loss of mud filtrates especially that of the WBM. The sands consist of irregular shape and were sieved with sieve shaker into a constant size diameter of $1.0 \mathrm{~mm}$. The sieved sands were washed, cleaned, weighed, dried in an oven and stored in different plastic bags of $200 \mathrm{~g}$. The density of the sands measured was $2.52 \mathrm{~g} / \mathrm{cm}^{3}$, which was determined using the standard (ASTM D4253$002006)$ testing method. The preparation of the sand samples started with cleaning it with tap water to ensure that no mud or other particles stuck around it, and the total sieved sands was $8 \mathrm{~kg}$. The sand particles as seen from close view are mostly coarse and spherical. As one of the factors, shape and size of cuttings have moderate effect on cuttings transport.

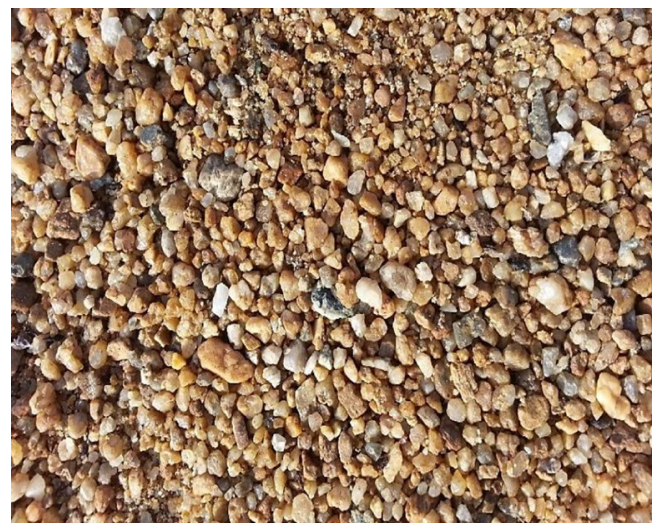

Fig. 2 Aquarium sands close view

\section{Formulation of drilling mud systems}

The formulation of BWBM and HWBM with fresh water as the continuous phase was carried out according to the American Petroleum Institute Recommended Practices of indoor fluid test criteria for water-based drilling fluids (API RP 13B1,2013 ) before it was tested in the cuttings transport flowloop. The formulation follows in ascending order according to Table 2. Hamilton beach mixer was used to stir each of the additives properly at least for 7 min when added.

\section{Measurement of drilling fluid properties}

The various mud properties were determined at room temperature before thermal aging according to the API RP 13B-1, 2013. The rheological properties were evaluated with Fann VG, model 35, Fann Instrument, Company (Houston, Texas). The filtration properties were measured using Fann API filter press at the operating pressure of $100 \mathrm{psi}$ and ambient temperature. The filtrates volumes were collected for each sample and the thickness of the filter cake was measured. The mud systems were formulated to achieve a density of $9.0 \mathrm{ppg}$. Equations (1) and (2) were used to calculate for the shear-stress $(\tau)$ and shear-rate $(\gamma)$ from Fann viscometer dial readings, while Eqs. (3)-(6) and Eqs. (7) and (8) were used to determine the rheological properties of the mud system using Bingham plastic model and Power law model, respectively.

$$
\begin{aligned}
& \text { Shear-stress }(\tau)\left(\mathrm{lb} / 100 \mathrm{ft}^{2}\right)=1.067 \times \phi, \\
& \text { Shear-rate }(\gamma)(1 / \mathrm{s})=1.704 \times \omega \\
& \mathrm{PV}(\mathrm{cP})=\phi_{600}-\phi_{300} \\
& \mathrm{YP}\left(\mathrm{lb} / 100 \mathrm{ft}^{2}\right)=\left(\phi_{300}-\mathrm{PV}\right) \\
& \mathrm{AV}(\mathrm{cP})=\phi_{600} / 2 \\
& \text { Effective viscosity, } \mathrm{AV}_{\mathrm{e}}(\mathrm{cP})=300 \times(\phi / \omega) \\
& \text { Flow behaviour index, } n=3.23 \times \log \left(\tau_{2} / \tau_{1}\right) \\
& \text { Consistency index, } K=\tau_{2} / 170.3^{n}
\end{aligned}
$$

Table 2 Drilling muds composition

\begin{tabular}{llll}
\hline Composition & Function & BWBM & HWBM \\
\hline Fresh water (ml) & Base fluid & 338.4 & 322.9 \\
Bentonite $(\mathrm{g})$ & Viscosity modifier and filtrates loss control agent & 15 & - \\
HLE powder $(\mathrm{g})$ & Fluid loss control agent and shale inhibitor & - & 15 \\
NaOH $(\mathrm{g})$ & pH control agent & 0.15 & 0.25 \\
PAC $(\mathrm{g})$ & Filtrates loss control agent & 0.25 & 0.25 \\
KCl $(\mathrm{g})$ & Shale inhibitor and water activity agent & 5 & 5 \\
Barite & Weight control agent & 24.6 & 40.3 \\
\hline
\end{tabular}


where $\phi$ is the Fann viscometer dial reading $\left(\mathrm{lb} / 100 \mathrm{ft}^{2}\right)$ and $\omega$ is the rotor speed (rpm). $\tau_{1}$ and $\tau_{2}$ are shear-stress measured at $\phi_{300}$ and $\phi_{600}$, respectively. $\phi_{300}$ and $\phi_{600}$ are Fann viscometer dial readings at $300 \mathrm{rpm}$ and $600 \mathrm{rpm}$, respectively. For the measurement of the muds lubricity using EP (extreme pressure) lubricity tester, the following Eqs. (9)-(12) were used:

$\mathrm{CoF}=\frac{\text { torque reading }}{100}$

$100=\frac{150 \mathrm{in} .-\mathrm{lbs} \text { torque wrench reading }}{1.5 \text { in. torque shaft lever arm }}$

$100=\frac{\text { standard water reading in metres }}{\text { water calibration in metres }}$

$100=\frac{\text { water reading in metres } \times \mathrm{CF}}{100}$

where $\mathrm{CF}$ and $\mathrm{CoF}$ are the coefficient factor and coefficient of friction, respectively.

\section{Thermal behaviour of the drilling mud systems}

Thermal properties of the prepared BWBM and HWBM were measured after aging the mud samples in a 4 roller oven at $150{ }^{\circ} \mathrm{F}$ for $16 \mathrm{~h}$. The rheological and filtration properties as well as the lubricity of the mud systems after thermal aging were again measured according to API recommended practices. HPHT filtrates loss test was carried out using HPHT filter press at the differential pressure of 500 psi and temperature of $250{ }^{\circ} \mathrm{C}$.

\section{Characterization}

The molecular structure of HLE sample was measured by FTIR spectra $\left(400-4000 \mathrm{~cm}^{-1}\right)$ with Perkin-Elmer Spectrum Two, (FTIR instruments, USA). The thermal properties of the HLE sample was measured on a Netzsch-STA 449 Jupiter instrument (TA instruments, Germany). About $20 \mathrm{mg}$ of the sample was heated from 30 to $800^{\circ} \mathrm{C}$ at a rate of $10^{\circ} \mathrm{C} /$ $\min$ in a protective nitrogen gas environment.

\section{Cuttings transport flow-loop set-up}

The cuttings transport flow-loop was fabricated to achieve the objective of this study, which was to compare the performance of BWBM, HWBM and fresh water on cuttings transport efficiency in a wellbore. The flow-loop and the layout of the flowloop are shown in Figs. 3 and 4, respectively. The flow-loop as shown in Fig. 3 was designed with a concentric annular test section of $16 \mathrm{ft}(4.9 \mathrm{~m})$ long acrylic pipe, with 3.5-in. $(0.089 \mathrm{~m}) \mathrm{ID}$ that acted as a simulated wellbore/casing. The static inner drilled PVC pipe was built with 2.4 in. $(0.609 \mathrm{~m})$ and sealed at both ends. The annulus test section was adjusted for five different hole-angles $\left(0^{\circ}, 45^{\circ}, 60^{\circ}, 75^{\circ}\right.$, and $\left.90^{\circ}\right)$ as shown in Fig. 5a-e during the experiments. The mud was

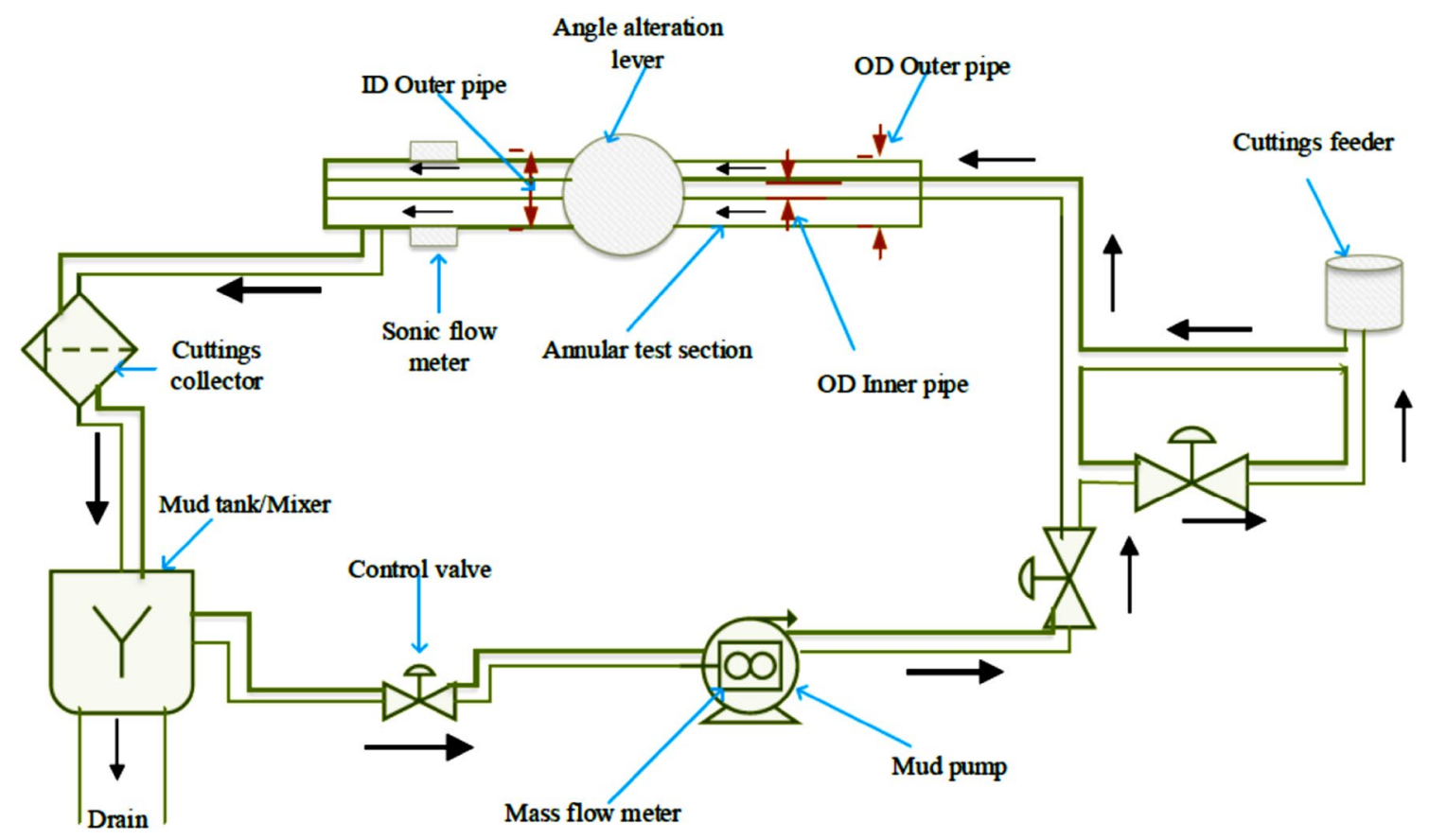

Fig. 3 Cuttings transport flow-loop 


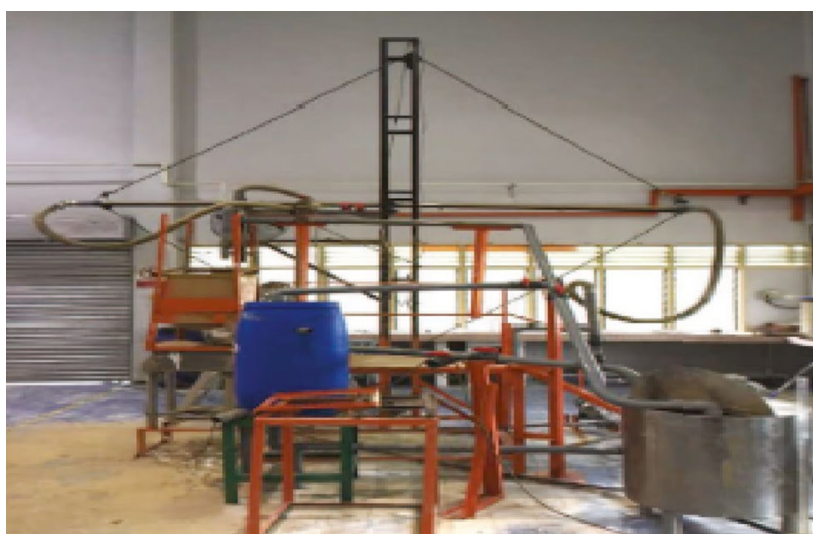

Fig. 4 Layout of the cuttings transport flow-loop

circulated using a 2-hp variable speed centrifugal pump with the capacity of about $20-42 \mathrm{~L} / \mathrm{min}$ (181.2-380.52 bbl/day). In order to trap the cuttings, separation tank was mounted after the annulus section, and was fitted with wire mesh of $0.2 \mathrm{~mm}$. The wire mesh was much smaller than the cuttings size in order to achieve efficient separation. The transported cuttings were collected after 7 min of circulation process and 5 min of recirculation to clean up any cuttings residue inside the flow pipes before a new run can be made. The CTE of each mud system after being tested where compared with the Eq. 13 below:

$\mathrm{CTE}=\frac{\text { weight of recovered cuttings }}{\text { weight of total injected cuttings }}=\frac{M \mathrm{r}}{M \mathrm{i}}$

\section{Results and discussion}

\section{FTIR analysis}

The FTIR results of the obtained HLE powder are shown in Fig. 6. The broad characteristics peak at $3320 \mathrm{~cm}^{-1}$ was assigned to the stretching vibration of hydrogen bonded hydroxyl phenol. The characteristics peak at $1005 \mathrm{~cm}^{-1}$ was attributed to the bending vibration of the $\mathrm{C}-\mathrm{H}$ bond. The sharp peak at $2960 \mathrm{~cm}^{-1}$ was assigned to the aliphatic $\mathrm{C}-\mathrm{H}$ group while the small peak at $2600 \mathrm{~cm}^{-1}$ was attributed to the aromatic $\mathrm{C}-\mathrm{H}$ group. The broad bands at $1660 \mathrm{~cm}^{-1}$ and $1450 \mathrm{~cm}^{-1}$ were for the stretching vibration of a carbonyl $(\mathrm{C}=\mathrm{O})$ group and for the $\mathrm{C}=\mathrm{C}$ bond of the naphthalene ring, respectively. These characteristics of the HLE corresponds with the molecular structure of Lawson pigment (Ananth et al. 2014).

\section{TGA analysis}

The thermal properties of the HLE powder are shown in Fig. 7. Two weight loss stages could be observed in Fig. 7.
The first transition was between the range of $80-250^{\circ} \mathrm{C}$ and the weight loss was about $14 \%$, which could be ascribed to the removal of water and hydrogen. The second transition was observed in the range of $350-500{ }^{\circ} \mathrm{C}$, and it showed a weight loss of about $61 \%$ (temperature around $390{ }^{\circ} \mathrm{C}$ ). The weight loss was attributed to the removal of coumaric acid (chemical constituent in HLE) and decomposition of HLE molecules.

\section{Bingham plastic model analysis}

Tables 3 and 4 show the results of Fann viscometer dial readings for both BWBM (without HLE) and HWBM (without bentonite). The units of the parameters in Tables 3 and 4 are the same as mentioned earlier.

\section{Mud pH}

The $\mathrm{pH}$ of the formulated drilling muds before and after thermal aging at $150^{\circ} \mathrm{F}$ for $16 \mathrm{~h}$ are shown in Fig. 8, and was found to be within the API recommended limit acceptable for drilling operations. The $\mathrm{pH}$ range (8.3-9.6) is necessary for the drilling muds additives especially the rheological properties to attain the right values. In addition, suitable $\mathrm{pH}$ level will not affect the HLE molecules to reduce their performance. With reference to the $\mathrm{pH}$ value of 5.0 in Table 1, HWBM has an increased $\mathrm{pH}$ value of 8.7 before thermal aging and was decreased to 8.3 after heating at $150{ }^{\circ} \mathrm{F}$ for $16 \mathrm{~h}$, while the BWBM has a pH of 9.6 before heating and 9.4 after heating. This is credited to the addition of $\mathrm{NaOH}$ into the muds for $\mathrm{pH}$ adjustment. The addition of $\mathrm{NaOH}$ in HWBM modified the chemical arrangement of HLE constituents when dissolving in water. However, the $\mathrm{pH}$ level of HWBM is lower compared to the $\mathrm{pH}$ of BWBM before and after thermal aging despite the contents of $\mathrm{NaOH}$ in the HWBM being higher than BWBM. The HLE when in solution with water takes out the atoms of hydrogen from its constituent's chemical configuration leading to reduction in pH (Moslemizadeh et al. 2015).

\section{Mud density}

For the mud density result shown in Fig. 9, both muds were built to achieve a density of $9.0 \mathrm{ppg}$ before thermal aging test. More amount of barite was added to HWBM in comparison to BWBM to achieve equal density with BWBM due to the low density of the HLE. Appropriate mud density is important to assess its effects on filtrates loss, filter cake properties, and formation damage. It can also influence drilled cuttings removal and promote wellbore cleaning by providing enough overbalance to ensure sufficient drilling rate is provided (Fattah and Lashin 2016). This is because the generated volume of drilled cuttings relies on drilling 

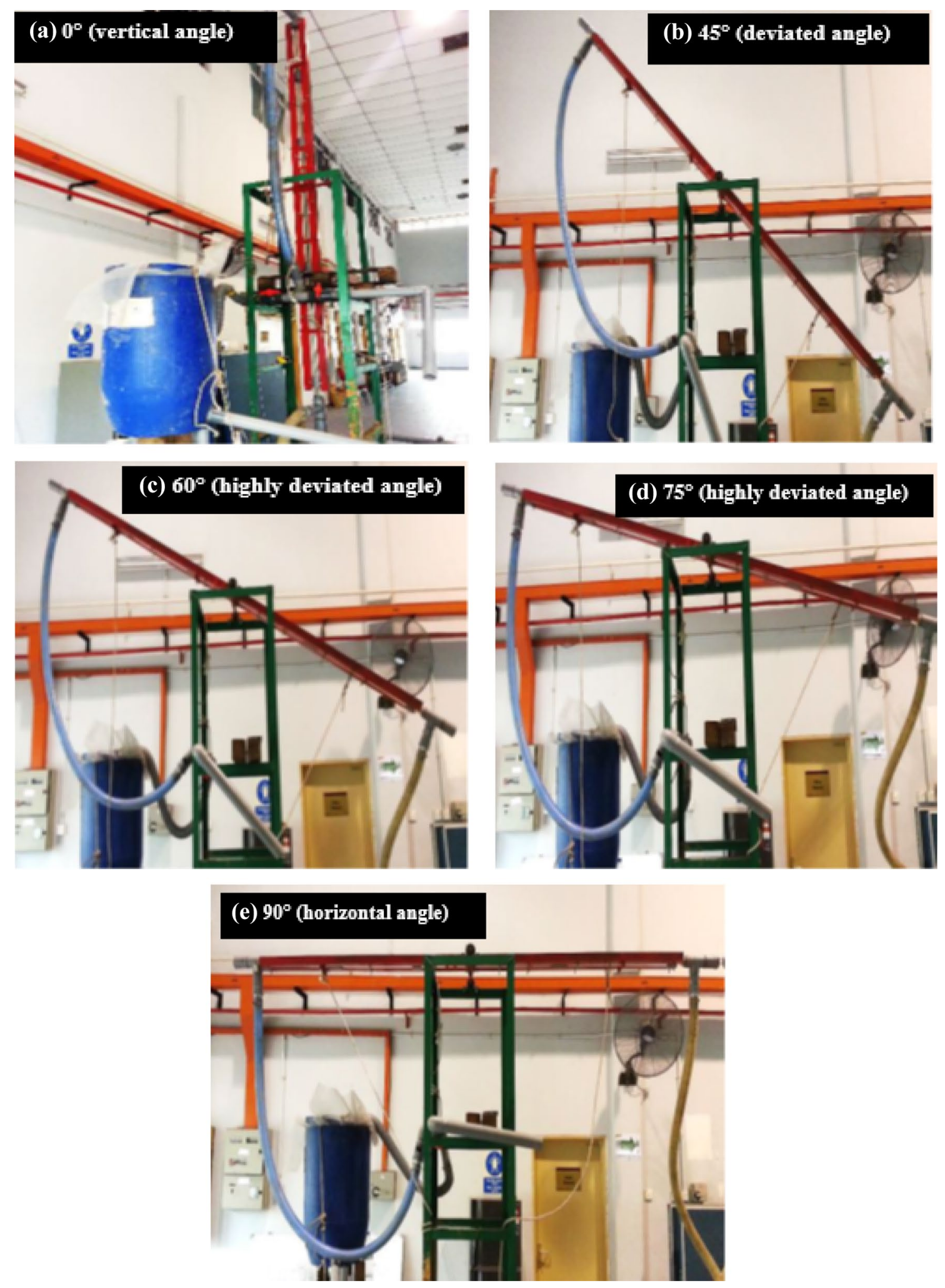

Fig. 5 a-e Representation of different tested hole-angles 


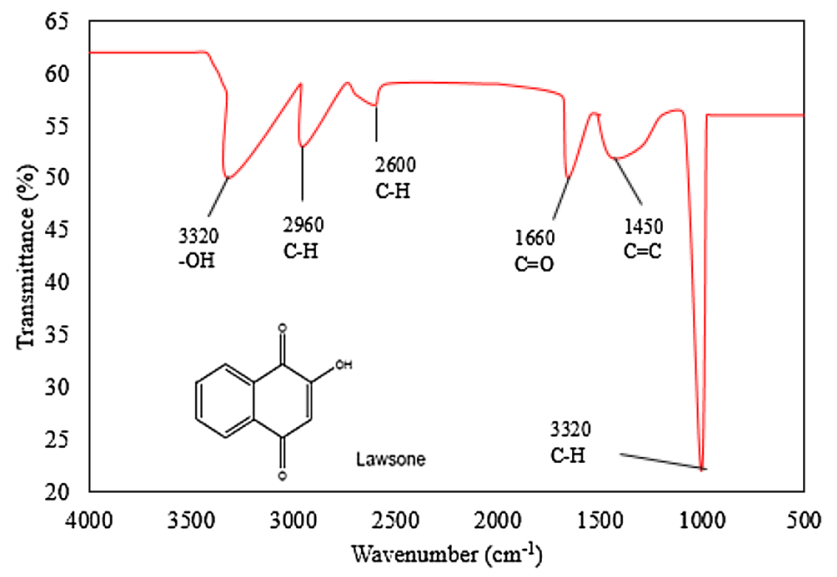

Fig. 6 FTIR spectra of HLE powder

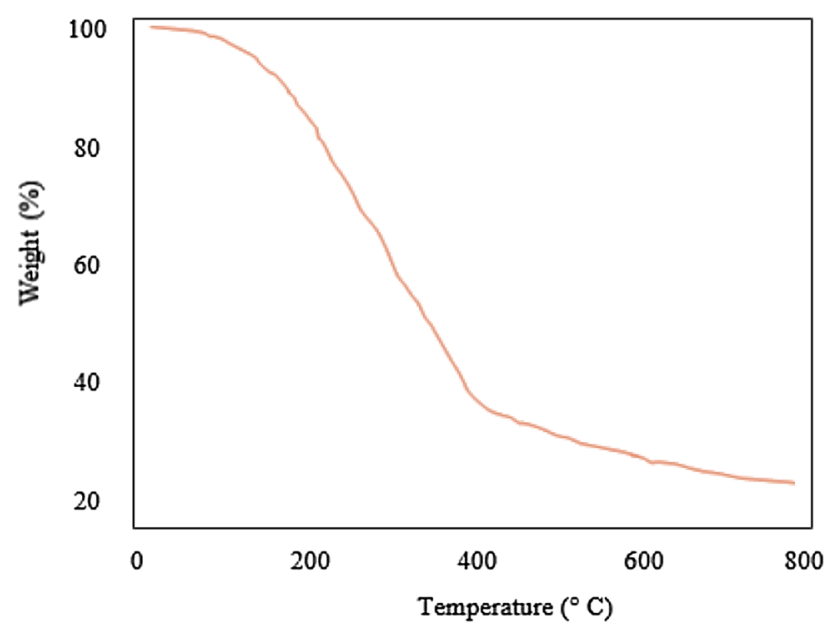

Fig. 7 Thermal properties of HLE powder

rate. Pumping thick fluid at fixed intervals while sustaining sufficient viscosity would promote cuttings lifting out of the hole. After heating the mud samples at $150^{\circ} \mathrm{F}$ for $16 \mathrm{~h}$, the density of the mud systems decreased. BWBM showed about 3.3\% decreased, while HWBM showed 2.2\% decreased, which indicated decomposition of some of the additives of the mud systems. There is no appreciable variation of density after heating between the two mud samples.

\section{Plastic viscosity and apparent viscosity}

For the PV result shown in Fig. 10 before and after heating, the PV of BWBM before heating was $7.4 \mathrm{cP}$ and 6.5 cP for HWBM. PV reflects the magnitude of the friction between the mass points in the fluid under laminar condition when the equilibrium of breakage and recovery of the structure in the fluid is reached (Caenn et al. 2017). It is a property that controls the degree of shear-stress to shearrate. Its main function in drilling mud is to provide information relating to a connection between the pumping rate and pump power requirement in a given well configuration. The PV value of BWBM before thermal aging was higher than that of HWBM, which may be due to the deflocculating characteristics of HLE and the presence of bentonite clay in BWBM. When bentonite clay solid gets in contact with water, it swells owing to its water absorption property, and this in turn increases its viscous nature. In addition, the PV and GS properties of bentonite muds system are achieved by clay-particle-to-clay-particle interactions. Clay particles in the water phase are attracted to each other and build up a structure that produces viscosity (Oseh et al. 2018). This is the reason for the higher value of PV in BWBM than that of HWBM. Lower volumes of drilling cuttings and solids offer faster penetration rate due to less resistance to fluid flow beneath the bit. Nonetheless, the PV should not be too low so that the drilled cuttings and other solids lifting from the hole to the surface will be possible (Gbadamosi et al. 2018b; Piroozian et al. 2012).

After heating the mud systems at $150^{\circ} \mathrm{F}$ for $16 \mathrm{~h}$, the PV of the bentonite bearing mud sample was slightly decreased with about $6.8 \%$, while that of HLE bearing mud sample was decreased by only $1.54 \%$, indicating a better thermal stability of HLE over bentonite. The chemical bonding of HLE contains Lawsone, which makes it more resilient at high temperature. In terms of apparent viscosity, both muds
Table 3 Fann viscometer dial readings of BWBM before and after thermal aging test at $150{ }^{\circ} \mathrm{F}$ for $16 \mathrm{~h}$

\begin{tabular}{|c|c|c|c|c|c|c|c|}
\hline \multicolumn{2}{|c|}{ Raw data } & \multicolumn{3}{|c|}{ Before aging } & \multicolumn{3}{|c|}{ After aging } \\
\hline$\omega$ & $\gamma$ & $\phi$ & $\tau$ & $\mathrm{AV}_{\mathrm{e}}$ & $\phi$ & $\tau$ & $\mathrm{AV}_{\mathrm{e}}$ \\
\hline 3 & 5.11 & 4.8 & 5.122 & 480 & 4.1 & 4.38 & 410 \\
\hline 6 & 10.22 & 7.2 & 7.682 & 360 & 6.5 & 6.94 & 325 \\
\hline 100 & 170.3 & 12.6 & 13.44 & 37.8 & 12.1 & 12.91 & 36.3 \\
\hline 200 & 340.6 & 16.4 & 14.30 & 24.6 & 14.7 & 15.69 & 22.1 \\
\hline 300 & 510.9 & 17.9 & 19.10 & 17.9 & 15.2 & 16.75 & 15.2 \\
\hline 600 & 1021.8 & 25.3 & 27.00 & 12.7 & 22.1 & 23.58 & 11.1 \\
\hline
\end{tabular}


Table 4 Fann viscometer dial readings of HWBM mud before and after thermal aging test at $150{ }^{\circ} \mathrm{F}$ for $16 \mathrm{~h}$

\begin{tabular}{|c|c|c|c|c|c|c|c|}
\hline \multicolumn{2}{|c|}{ Raw data } & \multicolumn{3}{|c|}{ Before aging } & \multicolumn{3}{|c|}{ After aging } \\
\hline 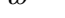 & $\gamma$ & $\phi$ & $\tau$ & $A v_{e}$ & $\phi$ & $\tau$ & $A V_{\mathrm{e}}$ \\
\hline 3 & 5.11 & 4.5 & 4.802 & 450 & 3.8 & 4.05 & 380 \\
\hline 6 & 10.22 & 6.8 & 7.256 & 340 & 5.6 & 5.98 & 280 \\
\hline 100 & 170.3 & 10.6 & 11.31 & 31.8 & 8.7 & 9.28 & 26.1 \\
\hline 200 & 340.6 & 13.3 & 14.19 & 20.0 & 11.9 & 12.70 & 17.9 \\
\hline 300 & 510.9 & 18.7 & 19.96 & 18.7 & 18.1 & 19.31 & 18.1 \\
\hline 600 & 1021.8 & 25.2 & 27.43 & 13.0 & 24.5 & 26.14 & 12.3 \\
\hline
\end{tabular}

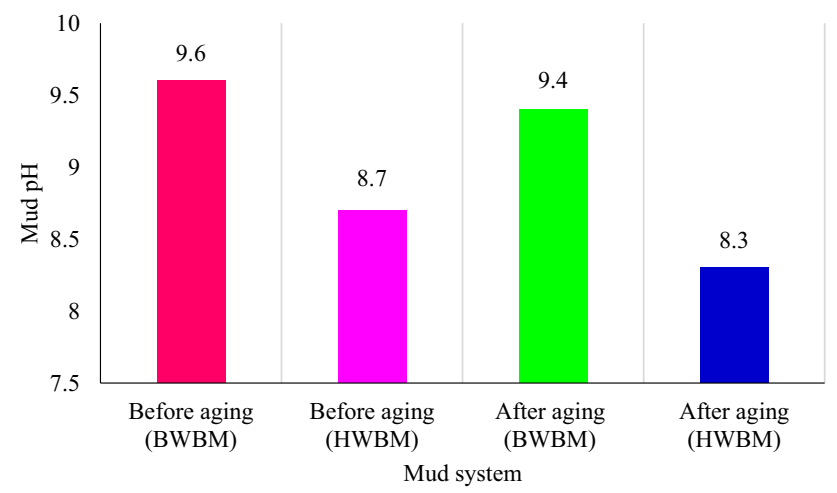

Fig. 8 Mud pH before and after thermal aging test at $150{ }^{\circ} \mathrm{F}$ for 16

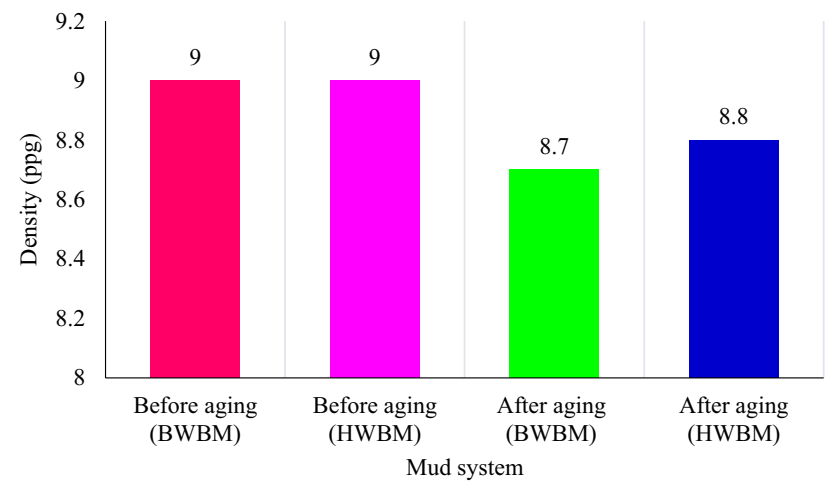

Fig. 9 Mud density before and after thermal aging test at $150{ }^{\circ} \mathrm{F}$ for $16 \mathrm{~h}$

exhibited almost similar shear-stress viscometer dial readings before thermal aging (Fig. 10). AV is the viscosity of drilling fluid at dial reading of $600 \mathrm{rpm}(1022 / \mathrm{s})$. It is a reflection of PV and YP combined. An increase in either or both will cause a corresponding increase in AV. Increasing values of shear-rate led to decreased of apparent viscosities values for the mud systems. These characteristic is important for the drilling mud lifting capacity of drilled cuttings. However, after heating the mud systems at $150^{\circ} \mathrm{F}$ for $16 \mathrm{~h}$

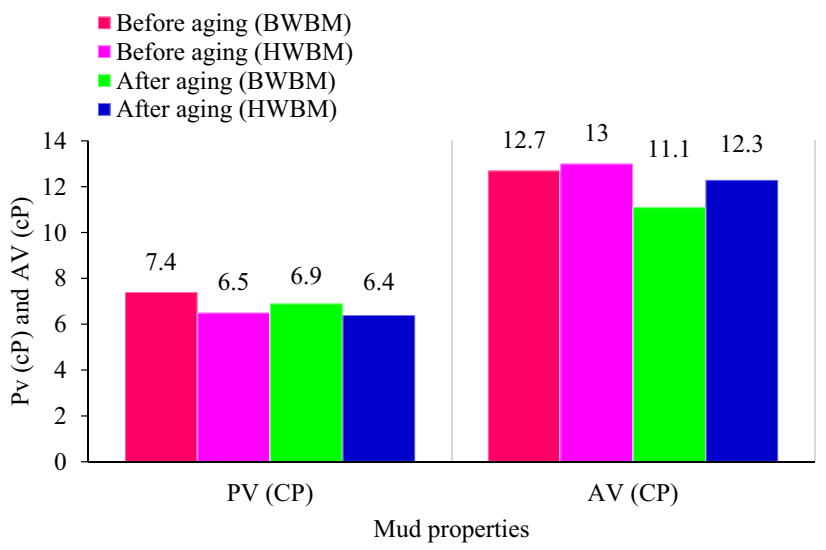

Fig. 10 Mud plastic and apparent viscosities before and after thermal aging test at $150{ }^{\circ} \mathrm{F}$ for $16 \mathrm{~h}$

(Fig. 10), the BWBM was decreased by $12.6 \%$, while the HWBM was slightly decreased by $5.4 \%$, indicating a higher decomposition of BWBM compared with HWBM.

\section{Yield point and YP/PV ratio}

The YP of the formulated drilling muds before and after thermal aging at $150{ }^{\circ} \mathrm{F}$ for $16 \mathrm{~h}$ are shown in Fig. 11. Anything that causes changes in the low shear-rate viscosities will be reflected in the YP. In other words, YP denotes the tendency of clay layers, such as bentonite to linking together and forming a flocculate structure. It indicates the ability of the drilling mud to carry cuttings to surface at dynamic condition. Moreover, frictional pressure loss is directly related to the YP. A higher YP implies higher pressure loss while the mud is being circulated (Darley and Gray 1981). Before thermal aging as shown in Fig. 11, the BWBM has a YP of $10.5 \mathrm{lb} / 100 \mathrm{ft}^{2}$, while the HWBM has a YP of $12.2 \mathrm{lb} / 100 \mathrm{ft}^{2}$. The lower value of YP of BWBM as compared to HWBM could be due to the inability of separated unit layers of bentonite clay particles to effectively link together with each other as a result of positive edge neutralization of the bentonite unit layer (Annis and Smith 1996). In addition, HLE

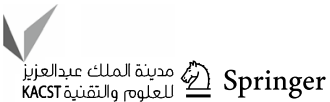




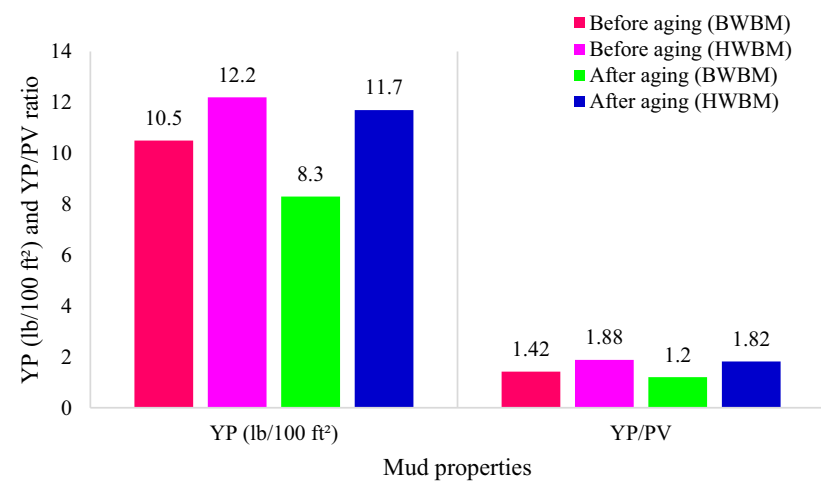

Fig. 11 Mud yield point and YP/PV ratio before and after thermal aging test at $150{ }^{\circ} \mathrm{F}$ for $16 \mathrm{~h}$

is a good deflocculant and can control the YP of the mud system. After heating the mud systems at $150^{\circ} \mathrm{F}$ for $16 \mathrm{~h}$ (Fig. 11), the YP of the BWBM was significantly reduced by $21 \%$ over only $4.1 \%$ of HWBM, indicating a better heat resistance of HWBM compared with that of BWBM.

The higher YP/PV ratio of HWBM in comparison with BWBM before and after thermal aging denotes its more shear-thinning characteristics, which could be more desirable for better cuttings transport compared with BWBM (Fig. 11). After thermal heating, the YP/PV ratio of BWBM was decreased by $15.5 \%$, while that of HLE bearing mud sample was slightly decreased by $3.2 \%$.

\section{0-s and 10-min gel strength}

The 10-s and 10-min GS of the formulated drilling muds before and after thermal aging at $150^{\circ} \mathrm{F}$ for $16 \mathrm{~h}$ are shown in Fig. 12, and was found to be within the operational limit for drilling operations. It was reported that the 10-min gel strength value for conventional WBM without nanoparticles should not exceed $6-8 \mathrm{lb} / 100 \mathrm{ft}^{2}$ (Guo et al. 2006). The GS is a shear-stress measurement needed to initiate fluid flow that has been in immobile state for a given period of time. In other words, any cause of change in the connection of clay layers of bentonite will improve or reduce its gelation tendency of dispersion (Annis and Smith 1996).

The HWBM showed a higher 10-s and 10-min GS values at both conditions than the BWBM. It contains $5.5 \mathrm{lb} / 100 \mathrm{ft}^{2}$ after heating and the BWBM has $5.0 \mathrm{lb} / 100 \mathrm{ft}^{2}$ for $10 \mathrm{~s}$. Both mud systems have $7.0 \mathrm{lb} / 100 \mathrm{ft}^{2} 10$-s GS before heating. The 10-min GS of HWBM was found to be $8.0 \mathrm{lb} / 100 \mathrm{ft}^{2}$ before heating and $5.8 \mathrm{lb} / 100 \mathrm{ft}^{2}$ after heating, while the BWBM showed $7 \mathrm{lb} / 100 \mathrm{ft}^{2}$ and $5.4 \mathrm{lb} / 100 \mathrm{ft}^{2}$ before and after heating, respectively. The higher values of 10 -s and 10-min GS of HLE bearing mud sample before and after thermal aging in comparison with BWBM could be linked to the deflocculating nature of HLE and aggregation of bentonite

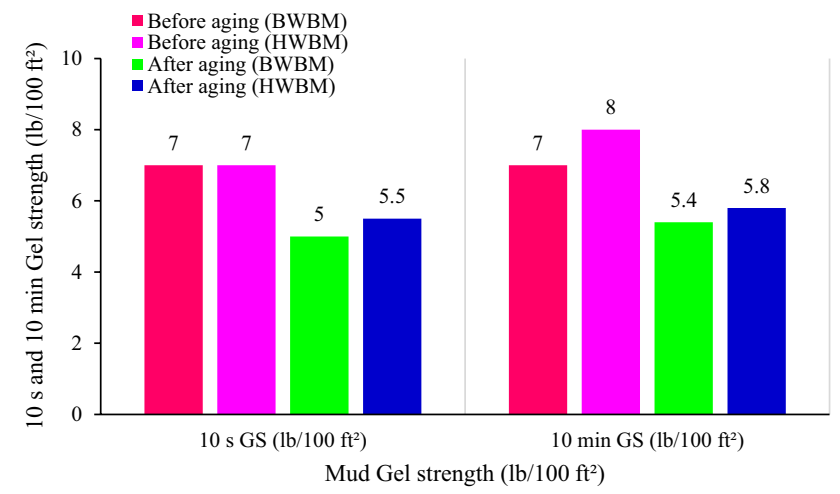

Fig. 12 10-s and 10-min gel strength before and after thermal aging test at $150{ }^{\circ} \mathrm{F}$ for $16 \mathrm{~h}$

clay particles in BWBM required to form gel networks. The presence of bentonite clay in BWBM could have caused a stronger gel-like character compared to HWBM without bentonite. The 10-s and 10-min GS of HLE bearing mud samples and bentonite bearing mud samples showed 'lowflat gel', which is desirable for drilling operation.

\section{API and HPHT filtration properties}

The API and HPHT filtrates loss volume of BWBM and HWBM systems are shown in Fig. 13. From Fig. 13, the API filtrates volume of BWBM was $7.1 \mathrm{ml}$, while that of HWBM was $5.4 \mathrm{ml}$, indicating that the BWBM has higher filtrates loss tendencies into the permeable formation than the HWBM. The relatively higher loss of filtrates volume in BWBM in comparison with HWBM is an indication that $\mathrm{KCl}$ presence needed for clay hydration inhibition induced high clay flocculation more than in HWBM leading to higher filtrates loss volume of BWBM (Zhong et al. 2011). Besides, TGA result showed that HLE can enhance the heat tolerance of the drilling mud system better than bentonite particles. The filtrates loss volume of conventional WBM is dependent

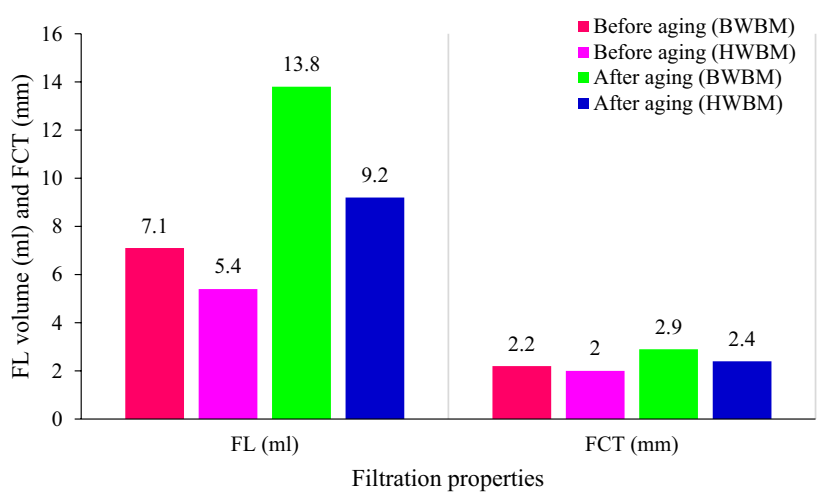

Fig. 13 API and HPHT filtration properties 
on the performance of the drilling fluid properties, in particular the plastic viscosity.

The obtained API filtrates loss volumes for the mud systems are relatively moderate for drilling operation. Low filtrates volume by improving the mud composition, deposition and thickness of the filter cake is one of the requirements of drilling muds. Conventional filtrates loss additives, such as partially hydrolyzed polyacrylamide (PHPA), carboxyl methyl cellulose (CMC) and PAC are in macro-sizes and cannot seal the nanopore throat of the wall of the wellbore effectively (Gbadamosi et al. 2018a). The filtrates volume of the mud systems was controlled by using PAC. After thermal aging the mud systems at $150^{\circ} \mathrm{F}$ for $16 \mathrm{~h}$, the HPHT filtrates volume of BWBM was increased to $13.8 \mathrm{ml}$ by $94.4 \%$ as compared to $9.2 \mathrm{ml}$ by $70.4 \%$ of HWBM (Fig. 13). Temperature has direct effect on filtration properties. Higher temperature gives the mud lower viscosities, and subsequently higher filtration properties. From Fig. 13, it can be observed that the mud systems have higher filtrates loss volume for HPHT filtrates volume test than API filtrates volume test.

The more filtrates loss into the formation, the more the filter cake thickness. The BWBM system has an API filter cake thickness of $2.2 \mathrm{~mm}$, while the HWBM samples API filter cake thickness was found to be $2.0 \mathrm{~mm}$ (Fig. 13). HWBM showed a better thin and low permeable mud cake thickness than BWBM. After heating, the filter cake thickness of both mud systems was increased. The HPHT filter cake thickness of BWBM and HWBM samples were $2.9 \mathrm{~mm}$ and $2.4 \mathrm{~mm}$, respectively. Based on this result, HWBM mud sample has better filtration control properties than BWBM at both API and HPHT conditions, and this property is desirable for drilling purposes as it could prevent stuck pipe incidents. The effect of a thick mud cake is that it reduces the effective diameter of the drilled wellbore, thereby increasing the area of contact between the drill pipe and the cake leading to greater risk of stuck pipe incidents (Gbadamosi et al. 2018b; Luz et al. 2017).

\section{Mud lubricity}

Figure 14 shows the coefficient of friction $(\mathrm{CoF})$ for the mud samples before and after thermal aging. It showed that the HLE bearing mud sample gave a better performance at both conditions as a lubricating agent than BWBM. Lubricating medium for the drill string while drilling the wellbore is one of the key functions of drilling mud (Aston et al. 1998). Lubricants are added to the drilling mud to reduce mechanical friction between contact surfaces, minimize risk of differential pipe stuck, and improve drilling rate (Aston et al. 1998). The HLE is expected to impact lubricating effect on the drilling mud. The BWBM exhibited a CoF of 0.30 before thermal aging and 0.33 after thermal aging at $150{ }^{\circ} \mathrm{F}$ for $16 \mathrm{~h}$, while the HWBM exhibited a CoF of 0.26 before

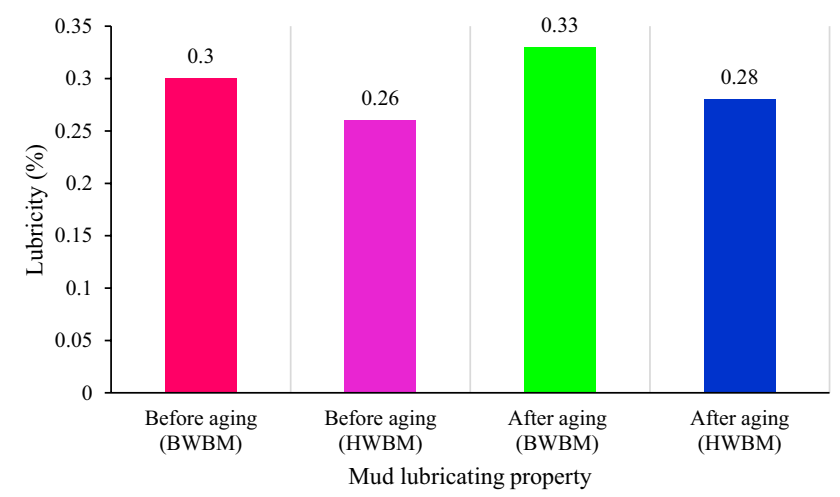

Fig. 14 Mud lubricity before and after thermal aging test at $150{ }^{\circ} \mathrm{F}$ for $16 \mathrm{~h}$

thermal aging and 0.28 after thermal aging at $150{ }^{\circ} \mathrm{F}$ for $16 \mathrm{~h}$.

Temperature influences the rheology of drilling muds, and higher temperatures increase the CoF. These values showed the less lubricity nature of the BWBM compared with HWBM. Typically, barite content in drilling muds increases CoF (Darley and Gray 1981). It appears that when temperature is increased, space between polymer molecules will rise, thereby, free volume between molecules becomes greater and the movement of molecules will then increase. This can decrease polymer coating over colloids, in particular barite. The typical value of CoF for conventional WBM is in the range of 0.17-0.28 (Darley and Gray 1981), and these range was achieved in this study with HLE bearing mud sample. It could also be that the heating of the mud samples at $150{ }^{\circ} \mathrm{F}$ caused plastic deformation and raises the $\mathrm{CoF}$ of both samples. Before the mud samples were subjected to thermal aging, HWBM showed about $13.3 \%$ more in torque reduction than the BWBM, and after heating the mud samples, it also showed better $\mathrm{CoF}$ reduction of about $15.2 \%$ more than the BWBM. This is because HLE in solution with water is chemically stable and can quickly attach on the clay and metal surfaces effectively due to its thermal stability and deflocculating characteristics by forming a film that can separate the rubbing surfaces in contact (Moslemizadeh et al. 2016).

\section{Power law model}

Figure 15 provides mathematical calculation of Power law formulas of Eqs. (7) and (8) for fluid flow behaviour index ' $n$ ' and fluid consistency index ' $K$ ' from the Fann viscometer dial readings for the mud samples before and after thermal aging for $16 \mathrm{~h}$ at $150{ }^{\circ} \mathrm{F}$. Before heating the mud samples, the ' $n$ ' and ' $K$ ' values were 0.486 and 0.931 for BWBM and 0.446 and 1.248 for HWBM, respectively. The parameter ' $K$ ' indicates the pump ability or thickness of the fluid, and

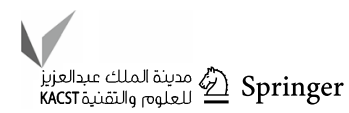




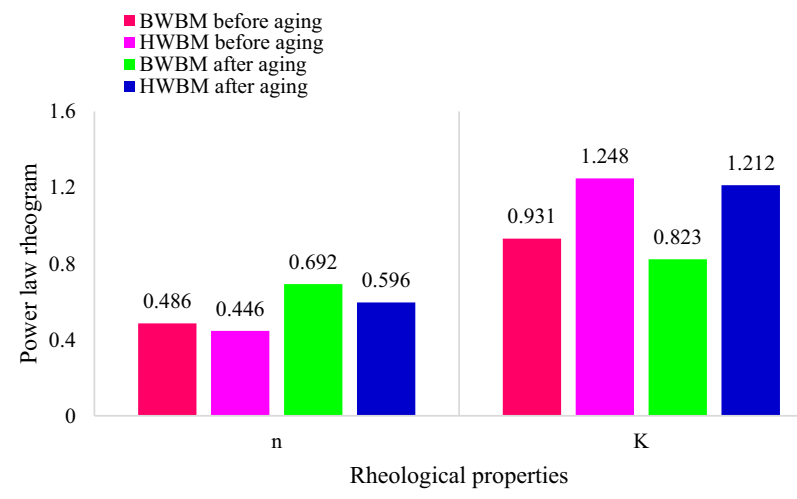

Fig. 15 Power law rheogram of parameters ' $n$ ' and ' $K$ ' of the mud systems

is considered equivalent to the fluid apparent viscosity. The parameter ' $n$ ' denotes the degree of non-Newtonian behaviour of the fluid, and it decreases from unity as the fluid exhibits more shear-thinning behaviour.

The parameter ' $K$ ' indicates how viscous is a given fluid, and it increases as the fluid becomes more viscous. The ' $n$ ' values for both mud samples are less than unity which indicates that the muds are pseudoplastic, showing shear-thinning behaviour (i.e., the apparent viscosity was decreased with increasing shear-rate). The parameter ' $n$ ' for HWBM shows more shear-thinning behaviour with about $8.2 \%$ than BWBM. HLE bearing mud sample is more viscous than BWBM with $25.4 \%$ according to the results of ' $K$ ' values of this study, and will be more desirable than BWBM to improve the carrying capacity of drilled cuttings.

After thermal aging of the mud samples, the shear-thinning effect of the mud system with HLE bearing mud sample was decreased by $25.2 \%$, while that of the BWBM was decreased by $29.8 \%$, owing to the thermal decomposition of some of the additives. In like manner, the parameter ' $K$ ' of HWBM was slightly decreased with about $2.8 \%$, whereas the BWBM showed a higher decreased of $11.8 \%$. Therefore, with these values of parameter ' $n$ ' and ' $K$ ', it is expected that the HLE bearing mud sample will give a better cuttings transport efficiency compared with BWBM. Both mud samples are non-Newtonian fluids and they exhibited shearthinning behaviour.

\section{Effects of plastic viscosity on cuttings transport efficiency}

The percentage of drilled cuttings recovered indicates the mud ability to lift cuttings from downhole to the surface. The experimental findings obtained revealed that plastic viscosity has positive influence for drilled cuttings removal. Figure 16a-e shows the relationship between cuttings transport efficiencies and plastic viscosities of the different fluid systems before thermal aging of the mud samples: Fresh water, (natural viscosifier with $1 \mathrm{cP}$ ), BWBM (with $7.4 \mathrm{cP}$ ) and HWBM (with $6.5 \mathrm{cP}$ ) at five (5) different hole-angles with different fluid velocities within the annulus. Increasing value of PV from $1 \mathrm{cP}$ to $6.5 \mathrm{cP}$ notably enhanced the CTE. A far-better enhancement on CTE was achieved with the use of $6.5 \mathrm{cP}$ (HWBM) than $1 \mathrm{cP}$ (fresh water).

However, the viscosity started to drop beyond the 6.5 $\mathrm{cP}$ when it was increased further to $7.4 \mathrm{cP}(\mathrm{BWBM})$. The obtained results are found to be consistent with the findings of some of the previous reserachers (Gbadamosi et al. 2018a; Piroozian et al. 2012; Onuoha et al. 2015; Zeidler 2013). According to their findings, the performance of drilling fluid reduces at higher viscosities for an increasing hole-angles. This is linked to the changes in the fluid flow regime characterized by Reynolds number, in which viscosity is one of the major governing factors contributing to the fluid flow. Increasing fluids viscosity at constant pump rate converts the flow regime from turbulent to transitional zone, and then to laminar flow or vice versa which often worsen hole-cleaning.

This mechanism often requires movement across a large number of Reynolds numbers and contributions of boundary layer effects. Thin boundary layer is desirable to induce higher shear-stress. Drilled cuttings are affected in the boundary layer by the difference in fluid velocity. Shearstress is a measure of these differences. It indicates the differential force experienced by cuttings when flowing through a pipe from the top to the bottom portion of the annulus. More cuttings will be transported if the boundary layer becomes thinner (more turbulent flow). On the other hand, if the fluid velocity within the annulus in a thick boundary layer flowing at the top of the cuttings is relatively equal to the velocity at the bottom, the shear-stress will be lowered, and cuttings is less likely to transport to the surface.

In addition, as the fluid travels in the pipe, the fluid friction between the adjacent molecules of the fluid transmits higher viscosity and minimizes fluid flow. This is because flow with high viscosity has a tendency to be less turbulent compared with a low viscosity. Though high inertial forces have a tendency to induce more turbulence, viscous forces has the propensity to repress turbulence by damping off the variations in the flow motion via friction; hence, reduced cuttings transportation (Boyou et al. 2019). Agreeing with the report of Suradi et al. (2015), in which they stated that cuttings transport can be enhanced when viscosity improves, which is in agreement with the viscosity of fresh water of $1 \mathrm{cP}$ of this study. It can be suggested that the bentonite clay layers linking together in BWBM have increased the bridging of particles and altered the composition and rheology of the mud, thereby resulting to higher viscosity in comparison with the viscosity of HWBM. Comparison between BWBM and HWBM including all the rheological and filtration parameters showed that HWBM provides the 

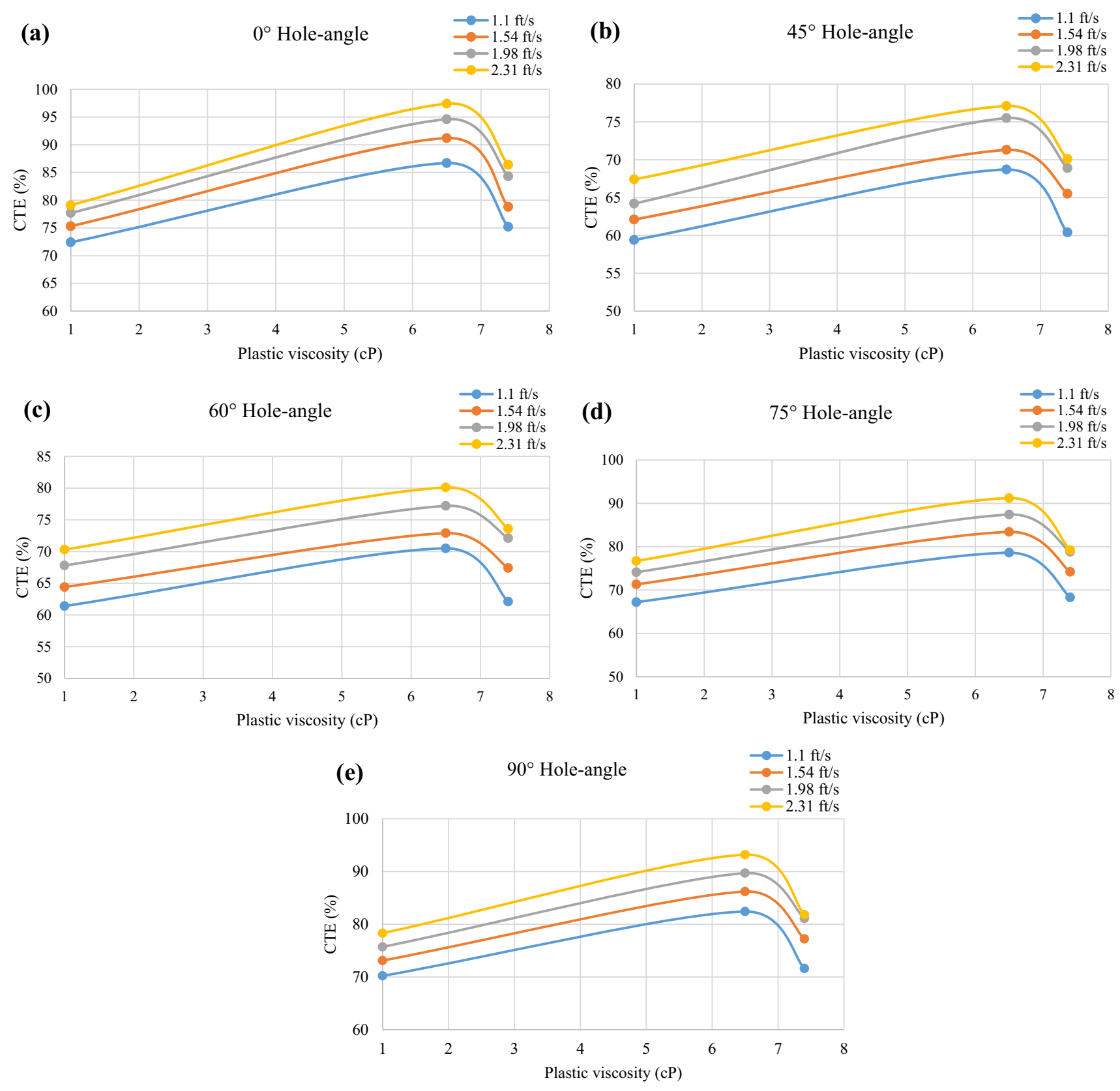

Fig. 16 Effect of viscosities on CTE at a $0^{\circ}$ hole-angle, $\mathbf{b} 45^{\circ}$ hole-angle, $\mathbf{c} 60^{\circ}$ hole-angle, $\mathbf{d} 75^{\circ}$ hole-angle, e $90^{\circ}$ hole-angle

best cuttings transport performance. Though, HLE bearing mud sample has lower PV compared with BWBM, other rheological values of HWBM, especially YP, YP/PV and 10-s and 10-min GS which are higher than that of BWBM contributed in transporting the cuttings.

\section{Effects of hole-angles on cuttings transport efficiency}

The experimental findings established that hole-angles have contributions in cuttings transportation to the surface.
From Fig. $17 \mathrm{a}-\mathrm{c}$, the flow curves denote the annular fluid velocities of fresh water, BWBM and HWBM. The distance between a given line to another indicate the effects of fluid velocity on the cuttings CTE at five different holeangles $\left(0^{\circ}, 45^{\circ}, 60^{\circ}, 75^{\circ}\right.$, and $\left.90^{\circ}\right)$. All the flow lines produced a downward behaviour by deviating from vertical $\left(0^{\circ}\right)$ to $45^{\circ}$ hole-angle, signifying that cuttings transports efficiency has waned. It could be observed that $45^{\circ}$ holeangle inclination recorded the lowest CTE, indicating that it is the most challenging hole-angle for cuttings transportation. This behaviour could be ascribed to the tendency of 

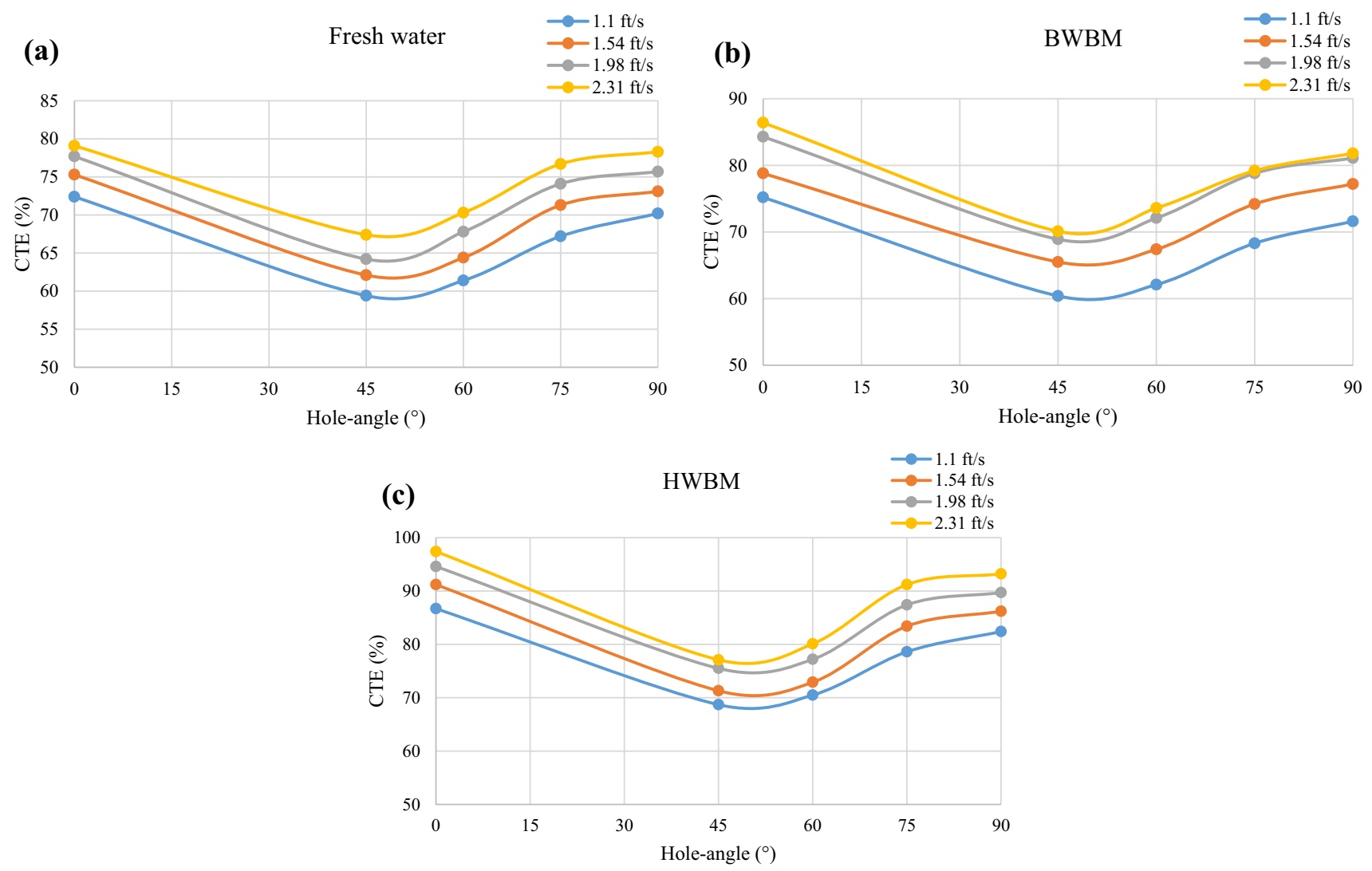

Fig. 17 Effect of different hole-angles on CTE using a water at $1 \mathrm{cP}, \mathbf{b}$ BWBM at $7.4 \mathrm{cP}, \mathbf{c} \mathrm{HWBM}$ at $6.5 \mathrm{cP}$

cuttings bed to slide recurrently and tumble down repeatedly at this hole inclination.

The result obtained in the hole-angles of this study is in agreement with published reports of the following authors (Oseh et al. 2018; Ismail et al. 2016; Onuoha et al. 2015; Ford et al. 1990; Piroozian et al. 2012; Ozbayoglu et al. 2010; Sifferman and Becker 1992). They reported that cuttings transportation is more challenging in highly deviated and horizontal wells drilling than in straight hole-angle. It could be suggested that in oil well drilling, the cuttings have the tendency to settle in the whole vertical portion of the annulus (hole-angle $0^{\circ}$ ), while in the highly deviated or horizontal section, they only have a few portions to settle. These phenomenon has been explained in many literatures (Ismail et al. 2016; Onuoha et al. 2015; Ford et al. 1990) to be caused by the effect of reduced fluid velocity component, which resists the cuttings slip velocity.

Two velocity vectors acts on drilled cuttings in opposite direction in vertical annulus, and they are gravity force pulling them downward and annular fluid velocity pushing them upward. At any time, the fluid velocity is able to surpass the effects of gravity on the drilled cuttings owing to synergistic relationship between the fluid velocity and the buoyant force triggered by difference in density, cuttings in the vertical annulus have the tendency to transports out of the annulus. This explained phenomenon is responsible for achieving the highest CTE at $0^{\circ}$ hole-angle of this study. In the highly deviated and horizontal portion of the annulus, the cuttings slip velocity vector can be grouped into two components; one working contrary to the fluid velocity, in which it decreases with increasing hole-angle, and the other component driving the cuttings towards the low sidewall of the annulus. This force acting on drilled cuttings increases as hole-angle increases, as can be seen in the range of $35^{\circ}-60^{\circ}$ hole-angles. When this happens, the drilled cuttings are forced towards the low side-wall of the annulus. Furthermore, as the hole-angle increases beyond $60^{\circ}$, the declining nature of the CTE observed at $35^{\circ}-60^{\circ}$ hole-angles was reversed, and the CTE started to increase again. The increasing trend continued to $90^{\circ}$ hole-angle. The sudden change of declining CTE from 35 to $60^{\circ}$ hole-angles to nonstop increase from $60^{\circ}$ to $90^{\circ}$ hole-angles could be credited to the fact that drilled cuttings at $60^{\circ}$ angle and above are stable and have reduced effects of gravity, indicating reduced drilled cuttings avalanched (constant sliding downwards of drilled cuttings). Therefore, appropriate hydraulic power could be needed for better cuttings transportation in highhole angles portion of the well. 


\section{Effects of annular fluid velocity on cuttings transport efficiency}

The flow curves obtained in Fig. 18a-c are found to be consistent with the reports of other research studies (Yeu et al. 2019; Oseh et al. 2018; Gbadamosi et al. 2018a, b; Hakim et al. 2018; Ismail et al. 2016; Onuoha et al. 2015; Duan et al. 2008; Noah 2013). Their findings revealed that CTE are increased with increasing annular fluid velocity. The fluid velocity at $2.31 \mathrm{ft} / \mathrm{s}$ for all hole-angles and viscosities investigated achieved the optimum hole-cleaning efficiency. To determine the velocity contributions of the different fluid systems on CTE, a comparison was made between the three fluid systems at different hole-angles with varied annular fluid velocities. At all hole-angles considered, the highest cleaning efficiency of the three muds were achieved at $0^{\circ}$ (vertical hole-angle) followed in succession by $90^{\circ}, 75^{\circ}, 60^{\circ}$ and finally hole-angle $45^{\circ}$ showing the worst CTE for all the mud samples. This is mainly due to the inclination of $45^{\circ}$ hole-angle and variation of the fluid velocities in the annulus. These velocities closer to the side-wall are much lower than those in the centre of the annulus. This difference in annular fluid velocities compels the drilled cuttings to move closer to the wall of the wellbore where there is

(a)

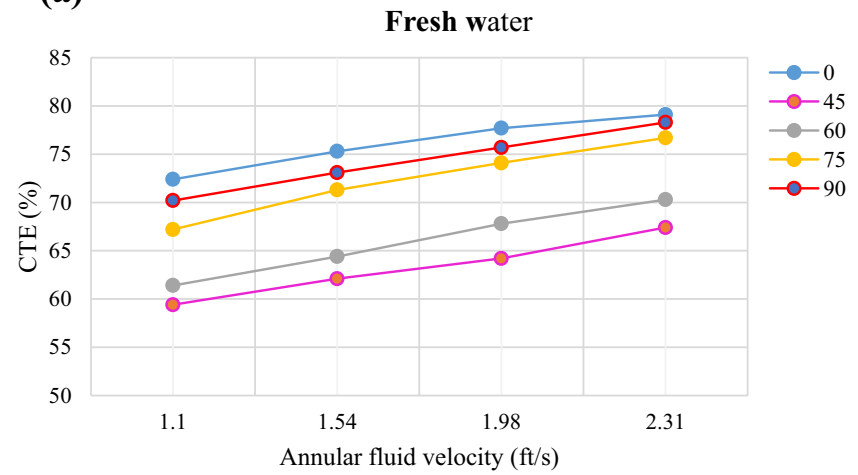

reduced flowrate, and consequently reduced performance of the mud sample.

\section{Cumulative performance of drilling muds on cuttings transport efficiency}

In comparing the cumulative performance of the three fluid systems on average CTE (Fig. 19), the optimum observed average CTE was achieved with HWBM. The least average CTE was achieved with fresh water, while BWBM have better average CTE than fresh water. Increased cuttings interactions with HLE have led to its more cuttings recovery to the surface compared with the other two fluids. The synergy existing between fluid velocity and buoyancy force in HLE bearing mud sample was higher compared to that of BWBM as the momentum of the flow in HWBM observed during the experiments was higher compared with fresh water and BWBM. Furthermore, HLE associated with WBM shows chemical stability in WBM as surface force easily balance the gravity force and adhered to drilled cuttings, resulting in increased drag force action to drilled cuttings. This action can easily lift drilled cuttings to the surface. For example, for vertical portion of the well $\left(0^{\circ}\right)$, HWBM on average transported about $5.43 \%$ and $9.94 \%$ more drilled cuttings than BWBM and fresh water, respectively, while BWBM (b)

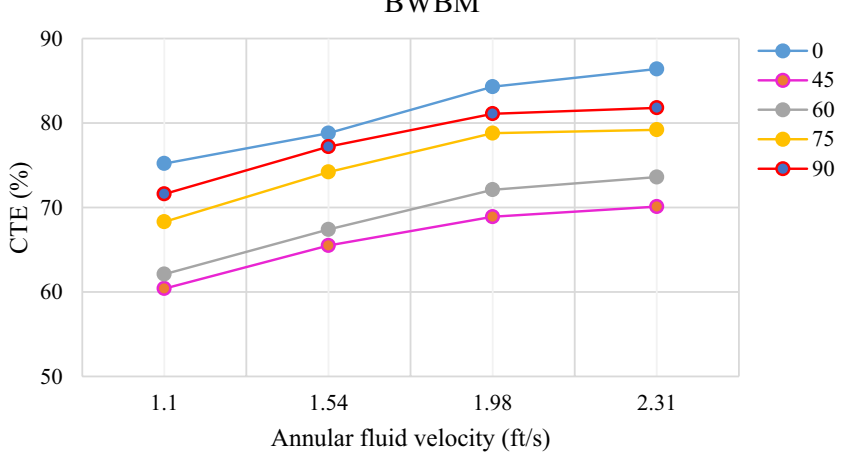

(c)

HWBM

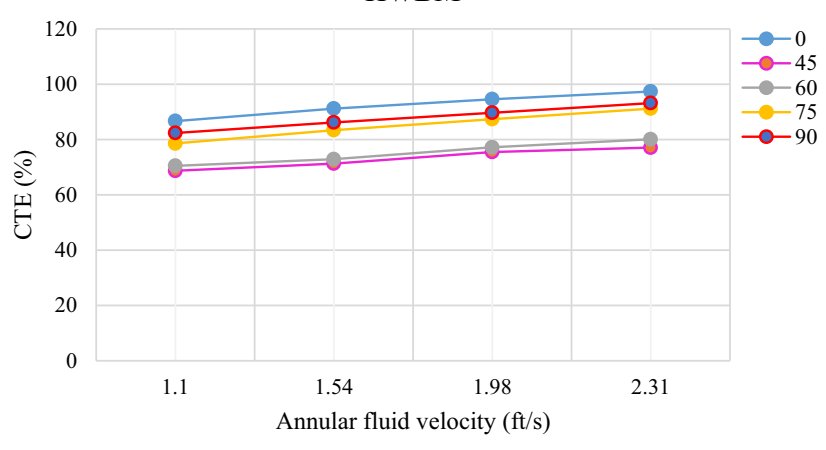

Fig. 18 Effect of annular fluid velocities on CTE using a fresh water at $1.0 \mathrm{cP}, \mathbf{b}$ BWBM at $7.4 \mathrm{cP}, \mathbf{c} \mathrm{HWBM}$ at $6.5 \mathrm{cP}$ 


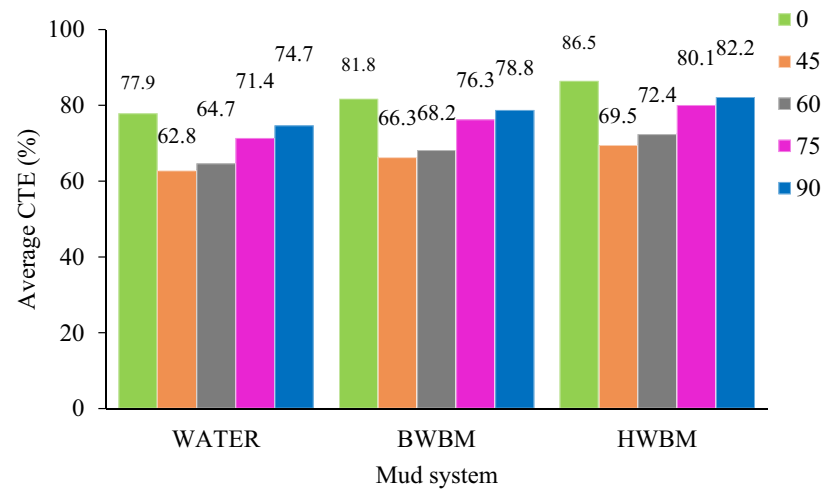

Fig. 19 Average CTE of the mud systems at all hole-angles

transported $4.77 \%$ more drilled cuttings than fresh water. Similar trend of result was achieved at $45^{\circ}, 60^{\circ}, 75^{\circ}$, and $90^{\circ}$. Therefore, it can be suggested that the HLE bearing mud sample contain improved rheological properties than BWBM which significantly enhance the mud's carrying capacity of drilled cuttings.

\section{Conclusion}

This study compared the performance of fresh water (natural viscosifier) of PV $1.0 \mathrm{cP}$ with HLE water-based mud of PV $6.5 \mathrm{cP}$ and bentonite water-based mud of PV $7.4 \mathrm{cP}$ on CTE without pipe rotation. The effects of different fluid viscosities, hole-angles and fluid velocities in the annulus on CTE were analysed. The main conclusions are drawn as follows:

1. The HLE bearing mud sample was compatible for high temperature conditions since it could sustain until $390{ }^{\circ} \mathrm{C}$ with a better rheological and filtration properties performance than BWBM. The chemical bonding of this HLE contains Lawsone which makes it more resilient at high temperature.

2. The use of HLE did give better performance than the BWBM in terms of rheological and filtration properties as well as lubricating property before and after thermal aging test at $150^{\circ} \mathrm{F}$ for $16 \mathrm{~h}$. Those properties, however, were found to be within the operational range or values.

3. Hole-angle $0^{\circ}$ (vertical angle) showed better CTE compared with other hole-angles investigated. Hole-angle $45^{\circ}$ was found to be the most critical hole-angle for cuttings transportation since the sliding of cuttings bed tends to occur as the well starts to deviate from vertical. It can be suggested that enough hydraulic power be given to this hole-angle for better cuttings transport and attention also be paid to high hole-angle portions of the well while preparing drilling mud.
Acknowledgements The authors wish to express their profound gratitude to the Research Management Centre of UTM and the Malaysian Ministry of Higher Learning for providing the needed fund through The UTM Geran Universiti Penyelidik-GUP Grant (VOT NO.: Q. J130000.2546.17H77; Ref. no: PY/2017/00885), and the facilities used for this research.

Open Access This article is distributed under the terms of the Creative Commons Attribution 4.0 International License (http://creativeco mmons.org/licenses/by/4.0/), which permits unrestricted use, distribution, and reproduction in any medium, provided you give appropriate credit to the original author(s) and the source, provide a link to the Creative Commons license, and indicate if changes were made.

\section{References}

Afolabi RO, Orodu OO, Efeovbokhan VE, Oluwatosin JR (2017) Optimizing the rheological properties of silica nano-modified bentonite mud using overlaid contour plot and estimation of maximum or upper shear stress limit. Cogent Eng 1287248:4

Aghajafari AH, Shadizadeh SR, Shahbazi K, Tabandehjou H (2016) Kinetic modeling of cement slurry synthesized with Henna extract in oil well acidizing treatments. Petroleum 2:96-207

Ali S, Hussain T, Nawaz R (2009) Optimization of alkaline extraction of natural dye from Henna leaves and its dyeing on cotton by exhaust method. J Clean Prod 17:61-66

Ananth S, Vivek P, Arumanayagam T, Murugakoothan P (2014) Natural dye extract of lawsonia inermis seed as photo sensitizer for titanium dioxide based dye sensitized solar cells. Spectrochim Acta Part A Mol Biomol Spectrosc 128:420-426

Annis MR, Smith V (1996) Drilling fluids technology. Exxon Company API recommended practice 13B-1 (2013) API standard practice for field testing drilling fluids

ASTM D4253-00 (2006) Standard test methods for maximum index density and unit weight of soils using a vibratory table. ASTM international, West Corishohocken

Aston M, Hearn P, McGhee G (1998) Techniques for solving torque and drag problems in today's drilling environment. In: Proceedings of the 1998 SPE annual technical conference, pp 55-68. https ://doi.org/10.2118/48939-MS

Avci H, Monticello R, Kotek R (2013) Preparation of antibacterial PVA and PEO nanofibers containing Lawsonia Inermis (henna) leaf extracts. J Biomater Sci Polym Ed 28 24:1815-1830

Belavadi MN, Chukwu GA (1994) Experimental study of the parameters affecting cutting transportation in a vertical wellbore annulus. SPE paper presented at the Western Regional Meeting, 23-25 March, Long Beach, California, USA, pp 23-27

Boyou NV, Ismail I, Wan Sulaiman WR, Haddad AS, Husein N, Hui HT, Nadaraja K (2019) Experimental investigation of hole cleaning in directional drilling by using nano-enhanced water-based drilling fluids. J Petrol Sci Eng 176:220-231

Caenn R, Darley HCH, Gray GR (2017) Introduction to drilling fluids. In: Composition and properties of drilling and completion fluids, pp 1-34

Chaudhary G, Goyal S, Poonia P (2010) Lawsonia inermis Linnaeus: a psychopharmacological review. Int J Pharmaceut Sci Drug Resour 2:91-98

Chilingarian GV, Vorabutr P (1983) Drilling and drilling fluids. Elsevier, Amsterdam, vol 37 50, pp 149-151

Cho H, Shah SN, Osisanya SO (2001) Effects of fluid flow in a porous cuttings-bed on cuttings transport 
Christiansen C (1991) From oil-based mud to water-based mud. SPE health, safety and environment in oil and gas exploration and production. The Hague, The Netherlands, pp 1-9

Darley HCH, Gray GR (1981) Composition and properties of oil well fluids. Gulf Publishing Company, Houston, vol 270, pp 495-498

Dosunmu A, Ogunrinde J (2010) Development of environmentally friendly oil based mud using palm oil and groundnut oil. SPE 140720 paper presented at the 34th Annual International Conference and Exhibition, 31 July-7 August, Tinapa-Calabar, Nigeria, pp 1123-1131

Duan MQ, Miska S, Yu MJ, Takach N, Ahmed R (2008) Transport of small cutting in extended reach drilling. SPE Drill Compl 23:258-265

Efficiency and Hydraulics. Paper SPE 71374 presented at the Annual Technical Conference and Exhibition, 30 September-3 October, held in New Orleans, Louisiana, pp 78-90

Elochukwu H, Gholami R, Dol SS (2017) An approach to improve the cuttings carrying capacity of nanosilica based muds. J Pet Sci Eng 152:210-216

Fattah KA, Lashin A (2016) Investigation of mud density and weighting materials effect on drilling fluid filter cake properties and formation damage. J Afr Earth Sci 117:345-357

Fereydouni M, Sabbaghi S, Saboori R, Zeinali S (2012) Effect of Polyanionic cellulose polymer nanoparticles on rheological properties of mud drilling. Int J Nanosci Nanotechnol 8:171-174

Ford JT, Peden JM, Oyeneyin MB, Gao E, Zarrough R (1990) Experimental investigation of drilled cuttings transport in inclined boreholes. SPE 20421, 65th SPE annual technical conference and exhibition, 23-26 September, New Orleans, LA, USA, pp 197-206

Garcia-Ochoa F, Santos VE, Casas JA, Gomez E (2000) Xanthan gum: production, recovery, and properties. Biotechnol Adv J 18:549-579

Gatlin C (1960) Petroleum engineering: drilling and well completions. Prentice-Hall, Englewood Cliffs, pp 125-129

Gavignet AA, Sobey IJ (1989) A model for the transport of cuttings in highly deviated wells. In: SPE 15417, presented at SPE annual technical conference and exhibition, 1-3 October, New Orleans, pp 24-31

Gbadamosi AO, Junin R, Abdalla Y, Agi A, Oseh JO (2018a) Experimental investigation of the effects of silica nanoparticle on hole cleaning efficiency of water-based drilling mud. J Pet Sci Eng 172:1226-1230

Gbadamosi AO, Junin R, Oseh JO, Agi A, Yekeen N et al (2018b) Improving hole cleaning efficiency using nanosilica in waterbased drilling muds. SPE-193401-MS. Nigeria Annual International Conference and Exhibition, 6-8 August, Lagos, Nigeria, pp 1-16

Guo J, Yan J, Fan W, Zhang H (2006) Applications of strongly inhibitive silicate-based drilling fluids in troublesome shale formations in Sudan. J Petrol Sci Eng 50:195-203

Hakim H, Katende A, Sagala F, Ismail I, Nsamba H (2018) Performance of polyethylene beads towards drill cuttings transportation in horizontal wellbore. J Pet Sci Eng 165:962-969

Ismail I, Onuoha MDU, Ismail AR, Piroozian A, Sulaimon WRW, Abbda SM (2016) Improving drilled cuttings lifting using polypropylene beads in water-based mud at different annular mud velocities. Int J Eng Technol 9:1-10

Labed A, Moummi N, Aoues K, Benchabane A (2016) Solar drying of henna (Lawsonia inermis) using different models of solar flat plate collectors: an experimental investigation in the region of Biskra (Algeria). J Clean Prod 112:45-52

Larsen TI, Pilehvari AA, Azar JJ (1997) Development of a new cuttings transport model for high-angle wellbores including horizontal wells. In: SPE annual technical conference and exhibition, 1-3 July, Denver, pp 129-136

Luz RCS, Fagundes FP, Balaban RC (2017) Water-based drilling fluids: the contribution of xanthan gum and carboxyl methyl cellulose on filtration control. Soc Pet Eng J 36 71:2365-2373

Mehrdad M, Hadieh RK, Mehdi N (2014) Synthesis and characterization of novel coloured polymers based on Lawson natural compound. Des Monomers Polym 17:784 789

Menezes RR, Marques LN, Campos LA, Ferreira HS, Santana LNL, Neves GA (2010) Use of statistical design to study the influence of $\mathrm{CMC}$ on the rheological properties of bentonite dispersions for water-based drilling fluids. Appl Clay Sci 49:34-41

Metzner AB (1985) Rheology of suspensions in polymeric liquids. J Rheol 29:739-775

Mirzai R (2015) Effect of Nano silica in brine treated PAC/XC/LVCMC Polymer-Bentonite fluid system. Faculty of Science and Technology, University of Stavanger, Master Thesis, pp. 23-25

Moslemizadeh A, Shadizadeh SR, Moomenie M (2015) Experimental investigation of the effect of henna extract on the swelling of sodium bentonite in aqueous solution. Appl Clay Sci 105:78-88

Moslemizadeh A, Shadizadeh SR, Moomenie M (2016) A natural dye in water-based drilling fluid: swelling inhibitive characteristics and side effects. Petroleum 3:1-12

Noah AZ (2013) Optimizing drilling fluid properties and flow rates for effective hole cleaning at high-angle and horizontal wells. J Appl Sci Res 9:705-718

Onuoha MDU, Ismail 1, Piroozian A, Mamat NS, Ismail AS (2015) Improving the cuttings transport performance of water-based mud. Sains Malaysiana 44:629-634

Oseh JO, Gbadamosi AO, Ogunyemi A, Omotara OO (2018) Transports of different cuttings sizes in a wellbore using henna and lignite materials. AJERD J Eng Res Dev 3:351-365

Ostovari A, Hoseinieh S, Peikari M, Shadizadeh SR, Hashemi S (2009) Corrosion inhibition of mild steel in $1 \mathrm{M} \mathrm{HCl}$ solution by henna extract: a comparative study of the inhibition by henna and its constituents (Lawsone, Gallic acid, $\alpha$-D-glucose and Tannic acid). Corros Sci 51:1935-1949

Ozbayoglu ME, Saasen A, Sorgun M, Svanes K (2010) Critical fluid velocities for removing cuttings bed inside horizontal and deviated wells. Pet Sci Technol 28:594-602

Piroozian A, Ismail I, Yaacob Z, Babakhani P, Ismail AR (2012) Impact of 1 drilling fluid viscosity, velocity and hole inclination on cuttings transportation in horizontal and highly deviated wells. J Pet Explor Prod Technol 149-156

Rabia H (1985) Oil-well drilling engineering: principles and practice. Graham \& Trotman, UK, pp 96-98

Sayindla S, Lund B, Ytrehus JD, Saasen A (2017) Hole-cleaning performance comparison of oil-based and water-based drilling fluids. J Pet Sci Eng 159:49-57

Semwal RB, Semwal DK, Combrinck S, Cartwright-Jones C, Viljoen A (2014) Lawsonia inermis L. (henna): ethnobotanical, phytochemical and pharmacological aspects. J Ethno pharmacol 155:80-103

Sifferman TR, Becker TE (1992) Hole cleaning in full-scale inclined wellbores. SPE Drill Eng 7(2):115-120

Sulaimon AA, Adeyemi BJ, Rahimi M (2017) Performance enhancement of selected vegetable oil as base fluid for drilling HPHT formation. J Pet Sci Eng 152:49-59

Suradi SR, Mamat NS, Jaafar MZ, Sulaiman WRW, Ismail AR (2015) Study of cuttings transport using stable foam based mud in inclined wellbore. J Appl Sci 5:808-814

Williams CE, Bruce GH (1951) carrying capacity of drilling mud. Trans AIME 19:111-120 
Yeu WJ, Katende A, Sagala F, Ismail I (2019) Improving hole cleaning using low density polyethylene beads at different mud circulation rates in different hole angles. J Nat Gas Sci Eng 61:333-343

Zeidler UH (2013) An experimental analysis of the transport of drilled particles. Soc Petrol Eng J 12(01):39-48
Zhong H, Qiu W, Huang W, Cao J (2011) Shale inhibitive properties of polyether diamine in water-based drilling fluid. J Petrol Sci Eng 78:510-515

Publisher's Note Springer Nature remains neutral with regard to jurisdictional claims in published maps and institutional affiliations. 